\title{
Field evaluation of a low-cost indoor air quality monitor to quantify exposure to pollutants in residential environments
}

\author{
Alejandro Moreno-Rangel ${ }^{1}$, Tim Sharpe ${ }^{2}$, Filbert Musau ${ }^{2}$, and Gráinne McGill ${ }^{2}$ \\ ${ }^{1}$ Mackintosh School of Architecture, The Glasgow School of Art, Glasgow, G1 6DE, UK \\ ${ }^{2}$ Mackintosh Environmental Architecture Research Unit, The Glasgow School of Art, Glasgow, G1 6DE, UK
}

Correspondence: Alejandro Moreno-Rangel (a.morenorangel1@student.gsa.ac.uk)

Received: 16 February 2018 - Revised: 28 March 2018 - Accepted: 17 April 2018 - Published: 9 May 2018

\begin{abstract}
Measurements of temporal and spatial changes to indoor contaminant concentrations are vital to understanding pollution characteristics. Whilst scientific instruments provide high temporal resolution of indoor pollutants, their cost and complexity make them unfeasible for large-scale projects. Low-cost monitors offer an opportunity to collect high-density temporal and spatial data in a broader range of households.

This paper presents a user study to assess the precision, accuracy, and usability of a low-cost indoor air quality monitor in a residential environment to collect data about the indoor pollution. Temperature, relative humidity, total volatile organic compounds $(t \mathrm{VOC})$, carbon dioxide $\left(\mathrm{CO}_{2}\right)$ equivalents, and fine particulate matter $\left(\mathrm{PM}_{2.5}\right)$ data were measured with five low-cost ("Foobot") monitors and were compared with data from other monitors reported to be scientifically validated.

The study found a significant agreement between the instruments with regard to temperature, relative humidity, total volatile organic compounds, and fine particulate matter data. Foobot $\mathrm{CO}_{2}$ equivalent was found to provide misleading $\mathrm{CO}_{2}$ levels as indicators of ventilation. Calibration equations were derived for $t \mathrm{VOC}, \mathrm{CO}_{2}$, and $\mathrm{PM}_{2.5}$ to improve sensors' accuracy. The data were analysed based on the percentage of time pollutant levels that exceeded WHO thresholds.

The performance of low-cost monitors to measure total volatile organic compounds and particulate matter $2.5 \mu \mathrm{m}$ has not been properly addressed. The findings suggest that Foobot is sufficiently accurate for identifying high pollutant exposures with potential health risks and for providing data at high granularity and good potential for user or scientific applications due to remote data retrieval. It may also be well suited to remote and larger-scale studies in quantifying exposure to pollutants.
\end{abstract}

1

Increasingly strict energy efficiency requirements have severe implications for buildings and indoor air quality (IAQ) (Yu and Kim, 2012). IAQ is crucial for peoples' health as we spend between 80 and $90 \%$ of our time inside buildings (Jones, 1999; Boyd, 2010) depending on the external weather conditions. Indoor air pollutants include carbon monoxide (CO), carbon dioxide $\left(\mathrm{CO}_{2}\right)$, volatile organic compounds (VOCs), particulate matter $\left(\mathrm{PM}_{2.5}\right.$ and $\left.\mathrm{PM}_{10}\right)$, and ozone $\left(\mathrm{O}_{3}\right)$ among others (Berry et al., 1996; Crump et al., 2002). Exposure to these can exacerbate existing conditions such as sensory irritation and other respiratory problems (WHO, 2000, 2010) and even increase the risk of developing cancer (Carrer et al., 2008). Residents are usually unaware of indoor pollution as many pollutants are imperceptible to humans. For instance, $85 \%$ of tobacco smoke is invisible to the human eye (Gee et al., 2013). It is necessary to monitor the quality of the indoor air to detect these pollutants and thus avoid the development of adverse health effects from inhaling pollutants. Accepted methods for measurements of indoor pollutants are based on filter-based gravimetric sensors or similar methods for particulate matter monitoring (Air Quality Expert Group, 2005), and infrared and photoionisa- 
tion gas sensors (Chou, 2000). While accurate and precise, such technologies are expensive, time-consuming, and often provide little temporal information. Methods for personal dust, VOC and $\mathrm{CO}_{2}$ scientific monitors often provide high temporal resolution but are expensive (> GBP 3500.00) and therefore result in limited spatial information (White, 2009). Although analytical instruments often provide high temporal resolution, they are intended for laboratory use and their requirement for skilled operators, high purchase and maintenance costs, slow response time, and large size (Chou, 2000) make them impractical for IAQ studies (Kularatna and Sudantha, 2008). Moreover, the accuracy of these instruments may be considered excessive for large-scale IAQ monitoring, where a principal objective is to investigate the relative concentration of pollutants and their trends. As the performance of low-cost sensors improves, gas sensors that are compact, robust, and low-cost, with versatile applications, could be used as alternatives (Lee, 2001) for certain monitoring projects and could be used to collect larger datasets.

Technologies such as metal oxide (MOx) semiconductor sensors (Herberger et al., 2010; Kadosaki et al., 2010; Liu et al., 2012), light scattering (Tong et al., 2015) and tin oxide sensors (Watson, 1984; Postolache et al., 2009), open platforms (Ferdoush and Li, 2014; Ali et al., 2016), and wireless networks (Yu et al., 2013) have been adapted into low-cost monitors, and even allow remote monitoring (Kahkonen et al., 1997). New low-cost (<GBP 200) monitoring technologies may also help building occupants understand the quality of air indoors. Low-cost IAQ monitors often implement real-time monitoring and visualisation for smartphones and tablets to help inform the users (Hasenfratz et al., 2012). There is, however, limited information regarding the performance of low-cost monitors in practice. Nevertheless, many low-cost IAQ monitors such as Speck, Dylos DC1700 Pro (Manikonda et al., 2016) and Dylos DC1100Pro (Semple et al., 2013b) have been tested in laboratory conditions, and the results show a significant agreement with scientific instruments.

Low-cost IAQ monitor manufacturers often include sensors for temperature, relative humidity, carbon dioxide, particulate matter, and total volatile organic compounds ( $t$ VOC), as evidenced by the Foobot, Speck, Awair, and Air Mentor Pro devices (see Table 1 for manufacturer specifications). These low-cost IAQ monitors use microprocessors to collect sensor output, convert the data, and store or transmit data wirelessly to a remote server. Many of these devices may use the same or very similar sensors. However, manufacturers use a variety of algorithms to convert the sensor output to a concentration of each pollutant. This calibration protocol can have a marked impact on sensor precision, accuracy, and bias. For instance, the SHARP GPY1010AU0F, a PM 2.5 sensor, was tested in laboratory conditions. It was found to be accurate; however, the study recommended that an improvement of the algorithm could enhance its performance (Wang et al., 2015). Another study evaluated the same sen- sor on a monitoring device using a different algorithm; the results showed better precision and linear response (Sousan et al., 2017).

The Dylos DC1700 showed a high agreement $\left(R^{2}=0.90\right)$ with SidePak AM510 in controlled chamber experiments (Semple et al., 2013a). It was also tested to quantify second-hand smoke concentrations in residential settings, where a good agreement $\left(R^{2}=0.86\right)$ to SidePak AM510 was observed (Semple et al., 2013b). Therefore, Dylos DC1700 particulate matter (PM) measurements have exhibited some agreement between fieldwork and laboratory results. Some limitations of this device include limited data storage (10000 data points), lack of remote access capabilities, and lack of multisensory measurements, such as temperature or relative humidity. $\mathrm{PM}_{2.5}$ measurements from Speck SPK18TH, however, showed discrepancies between the environmental chamber and field measurements. The device demonstrated high agreement for determination of cigarette smoke $\left(R^{2}=0.92\right)$ and Arizona test dust $\left(R^{2}=0.96\right)$ under laboratory settings (Manikonda et al., 2016). However, the performance of Speck SPK18TH was found to be inadequate when tested at low concentrations against a scientific instrument in the field, both indoors $\left(R^{2}=0.3\right)$ and outdoors $\left(R^{2}=0.1-0.2\right)$, showing an overestimation of $200 \%$ for indoor $\mathrm{PM}_{2.5}$, and $500 \%$ for outdoor compared to the Grimm 1.109 (Zikova et al., 2017). The accuracy of $\mathrm{PM}_{2.5}$ measurements from the Foobot (FBT0002100) device has only been evaluated in laboratory measurements, which showed a strong correlation $(r=0.99$ with a variation range of 5 to $8 \%$ ) with scientific instruments. Yet site-specific calibration may help to improve the accuracy of such sensors (Sousan et al., 2017).

The objective of this study is to evaluate the performance of the Foobot sensors, especially $\mathrm{PM}_{2.5}$ and $t \mathrm{VOC}$, in typical residential settings. The linear relationship and bias for temperature, relative humidity, $\mathrm{CO}_{2}, t \mathrm{VOC}$, and $\mathrm{PM}_{2.5}$ concentrations in a residential environment were assessed and compared to scientifically validated instruments (GrayWolf TG-502 TVOC, IQ-410, and PC-3016A). To the best of our knowledge, no study has yet evaluated the Foobot FBT0002100 sensors in field conditions. This paper compares the specifications of several low-cost IAQ monitors and explores in detail the components of the Foobot FBT0002100. Following this, indoor residential measurements from five Foobot FBT0002100 devices are compared to the GrayWolf instruments, and inter-device variances among the five Foobot devices are also analysed. Finally, field calibration equations are proposed to improve the accuracy of the Foobot FBT0002100 relative to the GrayWolf instruments. 
Table 1. Manufacturer specifications and characteristics for the low-cost consumer monitors.

\begin{tabular}{|c|c|c|c|c|c|c|c|}
\hline & & Air Mentor Pro & Awair & Dylos & Foobot & Netatmo & Speck 2.0 \\
\hline \multicolumn{2}{|c|}{ Model } & 8096-AP & AW6404 & DC1100 Pro & FBT0002100 & NWS01-EU & SPK18TH \\
\hline \multirow{2}{*}{\multicolumn{2}{|c|}{$\begin{array}{c}\text { Cost (GBP) } \\
{ }^{\circ} \mathrm{C}\end{array}$}} & 180.00 & 169.99 & 330.00 & 179.00 & 139.00 & 180.00 \\
\hline & & $\begin{array}{l}{\left[-20-80^{\circ} \mathrm{C}\right]} \\
\pm 0.1^{\circ} \mathrm{C}\end{array}$ & $\begin{array}{l}{\left[-40-125^{\circ} \mathrm{C}\right]} \\
\pm 0.3^{\circ} \mathrm{C}\end{array}$ & - & $\begin{array}{l}{\left[-40-125^{\circ} \mathrm{C}\right]} \\
\pm 0.4^{\circ} \mathrm{C}\end{array}$ & $\begin{array}{l}{\left[-0-50^{\circ} \mathrm{C}\right]} \\
\pm 0.3{ }^{\circ} \mathrm{C}\end{array}$ & Yes \\
\hline \multirow{4}{*}{ 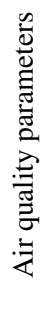 } & $\% \mathrm{RH}$ & {$[0-100 \% \mathrm{RH}]$} & [0-95\%RH] & - & {$[0-100 \% \mathrm{RH}]$} & {$[0-100 \% \mathrm{RH}]$} & Yes \\
\hline & $\mathrm{CO}_{2}$ & $\begin{array}{l} \pm 1.0 \% \mathrm{RH} \\
{[400-2000 \mathrm{ppm}]} \\
\pm 1.0 \mathrm{ppm}\end{array}$ & $\begin{array}{l} \pm 3.0 \% \mathrm{RH} \\
{[0-4000 \mathrm{ppm}]} \\
\pm 75 \mathrm{ppm}\end{array}$ & - & $\begin{array}{l} \pm 4.0 \% \text { RH } \\
{[400-6000 \mathrm{ppm}]} \\
\pm 1.0 \mathrm{ppm}\end{array}$ & $\begin{array}{l} \pm 3.0 \% \mathrm{RH} \\
{[0-5000 \mathrm{ppm}]} \\
\pm 50 \mathrm{ppm} \text { or } 5 \%\end{array}$ & - \\
\hline & $t \mathrm{VOC}$ & $\begin{array}{l}{[125-3500 \mathrm{ppb}]} \\
\pm 1.0 \mathrm{ppb}\end{array}$ & Yes & - & $\begin{array}{l}{[125-1000 \mathrm{ppb}]} \\
\pm 1.0 \mathrm{ppb}\end{array}$ & - & - \\
\hline & $\mathrm{PM}_{2.5}$ & $\begin{array}{l}{\left[0-300 \mu \mathrm{g} \mathrm{m}^{-3}\right]} \\
\pm 1 \mu \mathrm{g} \mathrm{m}^{-3}\end{array}$ & $\begin{array}{l}{\left[0-500 \mu \mathrm{g} \mathrm{m}^{-3}\right]} \\
(-)\end{array}$ & Yes & $\begin{array}{l}{\left[0-1300 \mu \mathrm{g} \mathrm{m}^{-3}\right]} \\
\pm 4 \mu \mathrm{g} \mathrm{m}^{-3} \\
\text { or } \pm 20 \%\end{array}$ & - & $\begin{array}{l}{\left[0-640 \mu \mathrm{g} \mathrm{m}^{-3}\right]} \\
(-)\end{array}$ \\
\hline & $\mathrm{PM}_{0.5}$ & - & - & Yes & - & - & - \\
\hline \multicolumn{2}{|c|}{ Remote storage } & Yes & Yes & No & Yes & Yes & Yes \\
\hline \multicolumn{2}{|c|}{ Internal storage } & Yes & Yes & Yes & No & No & Yes \\
\hline \multicolumn{2}{|c|}{ Wi-Fi connectivity } & No & Yes & No & Yes & Yes & Yes \\
\hline \multicolumn{2}{|c|}{ Remote data retrieval } & Yes & Yes & No & Yes & Yes & Yes \\
\hline \multicolumn{2}{|c|}{ Recording frequency } & $1 \mathrm{~min}$ & $5 \mathrm{~min}$ & $1 \mathrm{~min}$ & $5 \mathrm{~min}$ & $5 \min$ & $5 s-4 \min$ \\
\hline \multicolumn{2}{|c|}{ Dimensions (mm) } & $\begin{array}{l}106(\mathrm{H}), \\
115(\mathrm{~W}), \\
44.5(\mathrm{~L})\end{array}$ & $\begin{array}{l}90(\mathrm{H}), \\
160(\mathrm{~W}), \\
50(\mathrm{~L})\end{array}$ & $\begin{array}{l}177.8(\mathrm{H}), \\
114.3(\mathrm{~W}), \\
76.2(\mathrm{~L})\end{array}$ & $\begin{array}{l}172(\mathrm{H}), \\
71(\mathrm{D})\end{array}$ & $\begin{array}{l}155(\mathrm{H}), \\
45(\mathrm{D})\end{array}$ & $\begin{array}{l}89(\mathrm{H}) \\
114(\mathrm{~W}) \\
94(\mathrm{~L})\end{array}$ \\
\hline \multicolumn{2}{|c|}{ Weight (g) } & 498.95 & 453.59 & 1133.98 & 475 & 372 & 164.4 \\
\hline
\end{tabular}

\section{Low-cost IAQ monitors}

A web-based search for low-cost, consumer, air pollutant monitors (available in the US and European markets) was performed in early 2016. The most popular low-cost IAQ monitors are presented in Table 1. The Foobot FBT0002100 device was selected for detailed evaluation based on criteria as suggested by Chou (2000):

- availability (in the UK),

- capable of being installed in residential locations,

- remote connectivity and storage,

- dustproof and water-resistant,

- easy and minimal maintenance,

- easy to operate (no skilled person required),

- flexibility in data download,

- good responsiveness and quality of technical support,

- use of multisensory systems,

- long-lasting,

- low cost $(<$ UK GBP 200, including equipment and software),

- operationally stable,
- remote access to data, and

- rugged and corrosion resistant.

The Foobot was developed by AirBoxLab (Luxembourg) and measures five different air quality parameters with reference to maximum recommended values as defined by Foobot: $\mathrm{PM}_{2.5}\left(25 \mu \mathrm{g} \mathrm{m}^{-3}\right), t \mathrm{VOC}(300 \mathrm{ppb}), \mathrm{CO}_{2}(1300 \mathrm{ppm})$, temperature $\left(40^{\circ} \mathrm{C}\right)$, and relative humidity $(\mathrm{RH}, 60 \%)$. The device mechanism is simple; a microprocessor collects the electrical outputs from the sensors and converts them into data, which are then transmitted wirelessly to a remote server, where an algorithm is applied to derive the measured concentrations. Data may be lost if the wireless signal is interrupted, as the Foobot does not have internal data storage. The manufacturer hosts a website where the data uploaded can be visualised and downloaded (https://partner.foobot.io/, last access: 14 January 2018), though a monthly subscription is required for this service. Accessing the data for free is possible. Nevertheless, the user needs to develop his or her software with an application programming interface (API) provided by AirBoxLab, which allows up to 250 daily data requests to the server. AirBoxLab has developed a calibration algorithm for its sensors, details of which are not available to the public (personal communication, Inouk Bourgon, 2016). Figure 1 shows the Foobot and the sensors inside of the device.

Foobot uses the SHARP GP2Y1010AU0F sensor (Sharp Corporation, Japan) to measure $\mathrm{PM}_{2.5}$ which relies on natural convection to passively move air to the sensor, measuring particles with an aerodynamic diameter between 0.3 


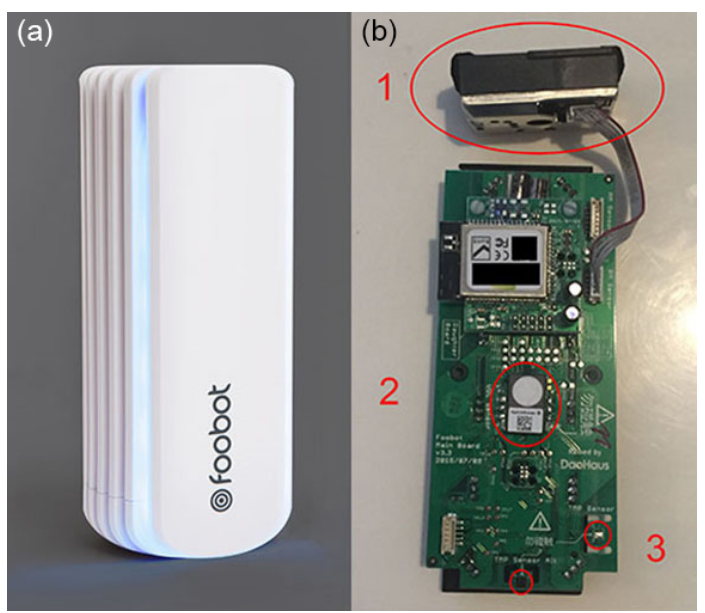

Figure 1. Foobot FBT0002100 monitor (a) and Foobot Main Board 3.3 (b) showing the SHARP GP2Y1010AUOF (1), the iAQ-COREC (2), and SHT20 (3). (a) from https://foobot.io (last access: 22 November 2017).

and $2.5 \mu \mathrm{m}$. The SHARP GP2Y1010AU0F was laboratorytested with two similar low-cost sensors, and showed the highest agreement with the SidePak-measured concentration $\left(R^{2}=0.9831\right.$ to 0.9838 in three different tests $)$ and a higher sensitivity to smaller particles. The researchers suggested that the SHARP GP2Y1010AU0F could be enhanced by modifying the flow system and amending the algorithm for particle concentrations (Wang et al., 2015).

The Foobot $t$ VOC sensor AMS iAQ-CORE-C (ams AG, Austria) measures a wide range of VOCs to predict $t \mathrm{VOC}$ (ppb). It lacks a $\mathrm{CO}_{2}$ sensor; however, an algorithm converts $t \mathrm{VOC}$ concentration as a $\mathrm{CO}_{2}$ equivalent (ppm). It has an Inter-Integrated Circuit $\left(I^{2} C\right)$ interface allowing the communication with the main chip. This sensor uses a microelectro-mechanical system allowing the metal oxide sensor to measure VOC concentrations continuously at $1 \mathrm{~s}$ intervals (AMS, 2015). Equations convert the signal output from the sensor to values of $t \mathrm{VOC}$ and $\mathrm{CO}_{2}$ equivalents (equations described at the AMS iAQ-CORE-C manual (AMS, 2015, pp. 10-11). The AMS iAQ-CORE-C does not report absolute values for any particular gas, but instead indicates the relative change in levels of reducing gases such as $\mathrm{CO}$ and a wide range of VOCs (Brown, 2017). This sensor has been used to control environmental monitoring systems (Kim et al., 2017) and smart health applications (Chan et al., 2017).

The Foobot temperature and relative humidity sensor is the SENSIRION SHT20 (Sensirion, Switzerland) with an $I^{2} C$ interface (see SENSIRION, 2014 for more information). This sensor has been on the market since May 2009 and has been widely accepted as a low-cost sensor for temperature and humidity. Since then, it has been used for smart home applications (Hernandez et al., 2014), for weather condition observation systems (An and Kang, 2014), and to control me-

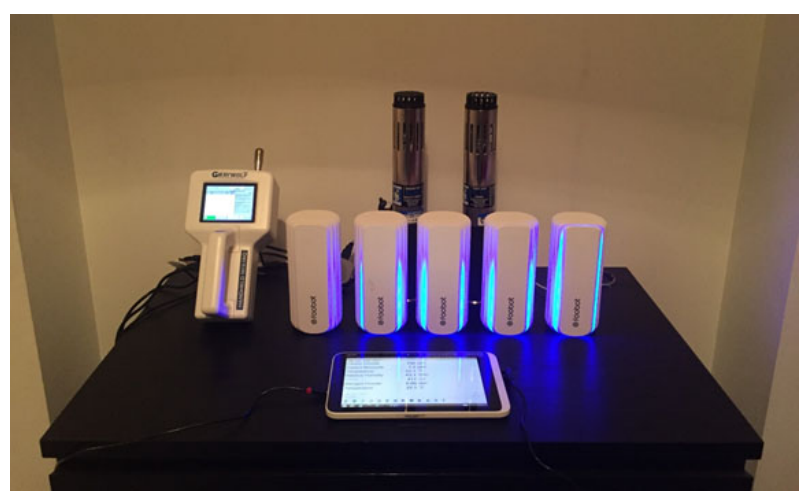

Figure 2. Test layout.

chanical ventilation with heat recovery systems (Matsuoka and Fisher, 2017).

\section{Method}

The study was undertaken following the guidelines of the ASTM D72974-14 Standard Practice for Evaluating Residential Indoor Air Quality (ASTM, 2014). The monitors were located at an approximate height of $0.90 \mathrm{~m}$ over the top of a drawer. Care was taken to ensure the monitors were placed away from direct pollutant sources, heat sources (such as cookers or radiators), and ventilation ducts or openings. Given the nature of the measurements and the desire to ensure that "typical" conditions were achieved, it was not possible to position the monitors in the centre of the room (see Fig. 2).

This study tests the accuracy of Foobot FBT0002100 temperature, relative humidity, particulate matter, and $t \mathrm{VOC}$ measurements by comparing the measurements of five Foobot FBT0002100 devices to measurements from the GrayWolf TG-502 TVOC, IQ-410, and PC-3016A. Table 2 shows the specification for the GrayWolf instruments. The monitors were set to measure simultaneously at $5 \mathrm{~min}$ intervals for $81 \mathrm{~h} 25 \mathrm{~min}$ (from 28 August 23:50 LT to 1 September 2017 11:25 LT) in an occupied bedroom (floor area $10.5 \mathrm{~m}^{2}$ ) of a modern flat in Glasgow, UK. The occupancy levels and activities were recorded by the occupants in a diary and this was used to contextualise the data, to ensure that typical conditions were represented, but this information was not used in the statistical analysis.

\section{Statistical analysis}

Data from each monitor were exported into Microsoft Excel for initial data inspection and to IBM SPSS Statistics for statistical analysis. The 5 min data pairs $(n=4895$ for each measure) across the study were assigned to either a calibration dataset ( $n=2448$ for each measure) or a validation dataset ( $n=2449$ for each measure). The Kolmogorov- 
Table 2. Manufacturer specifications and characteristics for the GrayWolf instruments.

\begin{tabular}{|c|c|c|c|c|}
\hline & & GrayWolf (VOC) & GrayWolf $\left(\mathrm{PM}_{2.5}\right)$ & GrayWolf $\left(\mathrm{CO}_{2}\right)$ \\
\hline \multicolumn{2}{|c|}{ Model } & TG-502 TVOC & PC-3016A & IQ-410 \\
\hline \multicolumn{2}{|c|}{ Cost (GBP) } & $3200.00^{1}$ & $2900.00^{1}$ & $3200.00^{1}$ \\
\hline \multirow{5}{*}{ 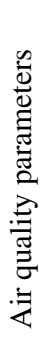 } & ${ }^{\circ} \mathrm{C}$ & {$\left[-10,70^{\circ} \mathrm{C}\right], \pm 0.3^{\circ} \mathrm{C}$} & {$\left[-10,70^{\circ} \mathrm{C}\right], \pm 0.3^{\circ} \mathrm{C}$} & {$\left[-10,70^{\circ} \mathrm{C}\right], \pm 0.3^{\circ} \mathrm{C}$} \\
\hline & $\% \mathrm{RH}$ & $\begin{array}{l}{[0-100 \% \mathrm{RH}], \pm 2 \% \mathrm{RH}} \\
<80 \% \mathrm{RH} \\
\pm 3 \% \mathrm{RH} \\
>80 \% \mathrm{RH}\end{array}$ & $\begin{array}{l}{[0-100 \% \mathrm{RH}], \pm 2 \% \mathrm{RH}} \\
<80 \% \mathrm{RH} \\
\pm 3 \% \mathrm{RH} \\
>80 \% \mathrm{RH}\end{array}$ & $\begin{array}{l}{[0-100 \% \mathrm{RH}], \pm 2 \% \mathrm{RH}} \\
<80 \% \mathrm{RH} \\
\pm 3 \% \mathrm{RH} \\
>80 \% \mathrm{RH}\end{array}$ \\
\hline & $\mathrm{CO}_{2}$ & No & No & {$[0-10000 \mathrm{ppm}], \pm 50 \mathrm{ppm}, \pm 3 \% \mathrm{rdg}$} \\
\hline & $t \mathrm{VOC}$ & $\begin{array}{l}{[0.1-10000.00 \mathrm{ppb}]} \\
\pm 1.6-2.0 \mathrm{ppb}^{2}\end{array}$ & No & No \\
\hline & $\mathrm{PM}_{2.5}$ & No & {$\left[0-4000000\right.$ particles $\left.\mathrm{ft}^{-3}\right] \pm 5 \%$} & No \\
\hline & $\mathrm{PM}_{0.5}$ & No & $100 \%$ for particles $>0.45 \mu \mathrm{m}$ & No \\
\hline \multicolumn{2}{|c|}{ Remote storage } & No & No & No \\
\hline \multicolumn{2}{|c|}{ Internal storage } & Yes & Yes, when connected to a tablet & Yes, when connected to a tablet \\
\hline \multicolumn{2}{|c|}{ Wi-Fi connectivity } & No & No & No \\
\hline \multicolumn{2}{|c|}{ Remote data retrieval } & No & No & No \\
\hline \multicolumn{2}{|c|}{ Recording frequency } & $1 \mathrm{~min}$ & $1 \mathrm{~min}$ & $1 \mathrm{~min}$ \\
\hline \multicolumn{2}{|c|}{ Dimensions (mm) } & $\begin{array}{l}300(\mathrm{H}) \\
50(\mathrm{D})\end{array}$ & $\begin{array}{l}63.5(\mathrm{H}) \\
127(\mathrm{~W}) \\
22.3(\mathrm{~L})\end{array}$ & $\begin{array}{l}300(\mathrm{H}) \\
50(\mathrm{D})\end{array}$ \\
\hline \multicolumn{2}{|c|}{ Weight (g) } & 700 & 1000.00 & 700 \\
\hline
\end{tabular}

${ }^{1}$ Require additional software ( GBP 1200.00) and a tablet (> GBP 500.00). ${ }^{2}$ Isobutylene equivalent.

Smirnov test rejected the hypothesis of normal distribution. Data were measured at intervals and were found to have a monotonic relationship. Therefore, Spearman's rank-order correlation $\left(r_{\mathrm{s}}\right)$ was applied to determine the correlation between the variables from each of the paired devices. This indicates the association from one device to another. The closer $r_{\mathrm{s}}$ is to unity, the more positive and direct is the association between devices. Correlations from 0.3 to 0.5 are considered as low positive (weak) correlation, 0.5 to 0.7 are considerate as a moderate (acceptable) positive correlation, from 0.7 to 0.9 as a high positive (strong) correlation and 0.9 to 1.00 as a very high positive association (very strong) (Mukaka, 2012).

The uniformity of data from different Foobot FBT0002100 was also determined by a Spearman's rank-order correlation. Additionally, to compare the differences between each of the measurements among the five different Foobot FBT0002100 monitors, the Kruskal-Wallis test, a nonparametric test, was applied to determine if there were statistically significant differences between them.

A regression analysis was performed to improve the accuracy of the Foobot FBT0002100 data relative to the GrayWolf data. Field calibration equations were then produced from the calibration dataset using the results from the GrayWolf instruments as dependent variables and the Foobot FBT0002100 as independent variables and tested on the validation dataset. An analysis in SPSS of the linear, quadratic, and cubic models was performed individually for each parameter to find the most accurate equation. A Bland-Altman analysis was then performed on the validation dataset to examine the correlation and agreement between data generated by the calibration equation and data obtained by the GrayWolf instruments. The Bland-Altman method calculates the mean difference between two methods of measurement (the "bias"), and $95 \%$ limits of agreement from the mean difference (1.96 SD) (Myles and Cui, 2007). From this process, a Bland-Altman plot (or difference plot) can be generated as a graphical method of comparing two measurements of the same variable.

Measurement of the extent to which data collectors (raters) assign the same score to the same variable is called interrater reliability. The interrater reliability of the agreement between the data generated by the calibration equation and the data from the GrayWolf instruments was tested using the Cohen's $\kappa$ test to account for the possibility of agreement happening by chance; the closer that $\kappa$ is to 1.00 the better agreement it has.

\section{Results}

\subsection{Inter-sensor analysis of low-cost and scientific IAQ monitors}

The measurements from the five Foobot FBT0002100 monitors were compared to those from the GrayWolf IQ-410, TG-502 TVOC, and PC-3016A. The results showed that the temperature measurements were very strongly related 


\section{GrayWolf to Foobot (1-5) temperature comparison}

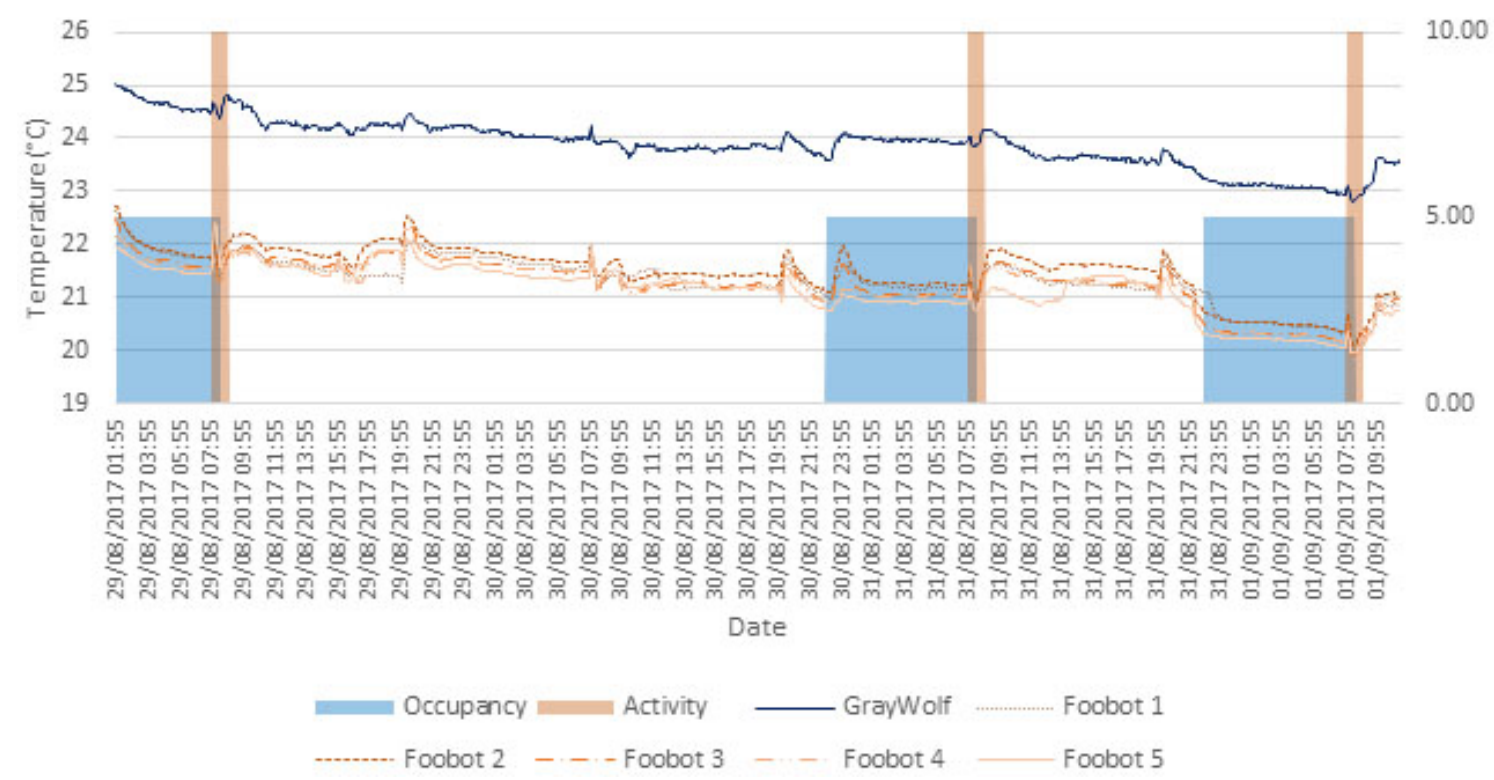

Figure 3. Temperature levels from 29 August to 1 September 2017 form the Foobot and GrayWolf instruments. (Activity describes the morning routine: showering, grooming, and changing.)

$\left(r_{\mathrm{s}}=0.833\right.$ to $\left.0.926, p<.001\right)$. Despite this, analysis of the temperature data showed that the Foobot FBT0002100 underestimated temperature (mean $(M)=2.59^{\circ} \mathrm{C}, 95 \%$ confidence interval from 2.40 to $2.73{ }^{\circ} \mathrm{C}$; Fig. 3). Knowledge of inter-sensor variability is important for the reliability of sensors in practice. Analysis of the temperature data from the five Foobot FBT0002100 monitors identified a very significant uniformity $\left(r_{\mathrm{s}}=0.833\right.$ to $\left.0.926, p<.001\right)$ and low variability $\left(M=0.16^{\circ} \mathrm{C}\right.$, from 0.16 to $\left.0.33^{\circ} \mathrm{C}\right)$ between the different temperature sensors.

A very strong relationship $\left(r_{\mathrm{s}}=0.935\right.$ to $\left.0.948, p<.001\right)$ was observed for relative humidity measurements from the five Fooboot FBT0002100 and the GrayWolf monitors. Very low variability was observed between Foobot and GrayWolf monitors, given that the Foobot FBT0002100 underestimated the relative humidity levels by $0.01 \% \mathrm{RH}$ (from -0.78 to $1.08 \%$ RH, Fig. 4). Inter-sensor analysis between the five Foobot monitors showed a very strong uniformity $\left(r_{\mathrm{s}}=0.985\right.$ to $\left.0.991, p<.001\right)$ and low variability $(M=0.52 \% \mathrm{RH}$, from -1.86 to $0.75 \% \mathrm{RH})$ of the relative humidity sensor.

Analysis of the $t \mathrm{VOC}$ measurements from the five Foboot monitors and the GrayWolf TG-502 TVOC showed a significant relationship $\left(r_{\mathrm{s}}=0.827\right.$ to $\left.0.869, p<.001\right)$. A very low variability between the five Foobot monitors was observed, but the Foobot underestimated the $t$ VOC levels by $22.12 \mathrm{ppb}$ (from 12.79 to $28.20 \mathrm{ppb}$, Table 3, Fig. 5). Inter-sensor analysis between the five Foobot monitors showed a very strong uniformity $\left(r_{\mathrm{s}}=0.892\right.$ to $\left.0.974, p<.001\right)$ and low variabil- ity $(M=-7.05 \mathrm{ppb}$, from -15.43 to $-1.67 \mathrm{ppb})$ between the different $t \mathrm{VOC}$ sensors.

Analysis of the $\mathrm{CO}_{2}$ (equivalent from $t \mathrm{VOC}$ ) data from the Foobot monitors and the GrayWolf IQ-410 showed that the Foobot $\mathrm{CO}_{2}$ levels differed from those measured by the GrayWolf instrument. A weak but significant correlation $\left(r_{\mathrm{s}}=0.397\right.$ to $\left.0.525, p<.001\right)$ was observed. The Foobot monitors underestimated the $\mathrm{CO}_{2}$ concentrations $(M=147.08 \mathrm{ppm}$, from 99.08 to $155.00 \mathrm{ppm}$, Fig. 6), a factor which could lead to problems in assessing ventilation based on $\mathrm{CO}_{2}$ levels. The percentage of time $\mathrm{CO}_{2}>1000 \mathrm{ppm}$ was considerably different between the GrayWolf IQ-410 and the five Foobot monitors (Table 4). Inter-sensor analysis of the five Foobot monitors showed a very strong uniformity $\left(r_{\mathrm{s}}=0.892\right.$ to $\left.0.973, p<.001\right)$ and a low variance ( $M=25.54 \mathrm{ppm}$, from 5.99 to $55.92 \mathrm{ppm})$ between the different $\mathrm{CO}_{2}$ measurements.

$\mathrm{PM}_{2.5}$ measurements from the five Foobot monitors and the GrayWolf PC-3016A were significantly related $\left(r_{\mathrm{s}}=0.787\right.$ to $\left.0.866, p<.001\right)$ to each other. Despite this, analysis of the data showed that the Foobot overestimated $\mathrm{PM}_{2.5}$ concentrations $\left(M=-1.4826 \mu \mathrm{g} \mathrm{m}^{-3}\right.$, from -1.4783 to $-1.4870 \mu \mathrm{g} \mathrm{m}^{-3}$, Table 5, Fig. 7). A higher degree of agreement between the types of devices is addressed in the following section. Inter-sensor analysis of the five Foobot monitors showed that there was an acceptable uniformity $\left(r_{\mathrm{s}}=0.576-0.843 p<.001\right)$ and a low variance $\left(M=-1.4826 \mu \mathrm{g} \mathrm{m}^{-3}\right.$ from -0.0068 to $\left.0.0084 \mu \mathrm{g} \mathrm{m}^{-3}\right)$ between the different $\mathrm{PM}_{2.5}$ sensors. 
Table 3. Summary statistics for $t$ VOC calibration dataset divided by instruments.

\begin{tabular}{lrrrr}
\hline Instrument & $\begin{array}{r}t \text { VOC mean } \\
(\mathrm{ppb})\end{array}$ & $\begin{array}{r}t \text { VOC min. } \\
(\mathrm{ppb})\end{array}$ & $\begin{array}{r}t \text { VOC max. } \\
(\mathrm{ppb})\end{array}$ & $\begin{array}{r}\% \text { time } \\
>300 \mathrm{ppb}\end{array}$ \\
\hline GrayWolf TG-502 TVOC & 176.4 & 143 & 549 & $0.82 \%$ \\
Foobot FBT0002100 A & 158.7 & 125 & 369 & $0.41 \%$ \\
Foobot FBT0002100 B & 161.3 & 125 & 357 & $0.41 \%$ \\
Foobot FBT0002100 C & 164 & 125 & 350 & $0.61 \%$ \\
Foobot FBT0002100 D & 165.7 & 125 & 376 & $0.61 \%$ \\
Foobot FBT0002100 E & 174.1 & 125 & 413 & $2.25 \%$ \\
\hline
\end{tabular}

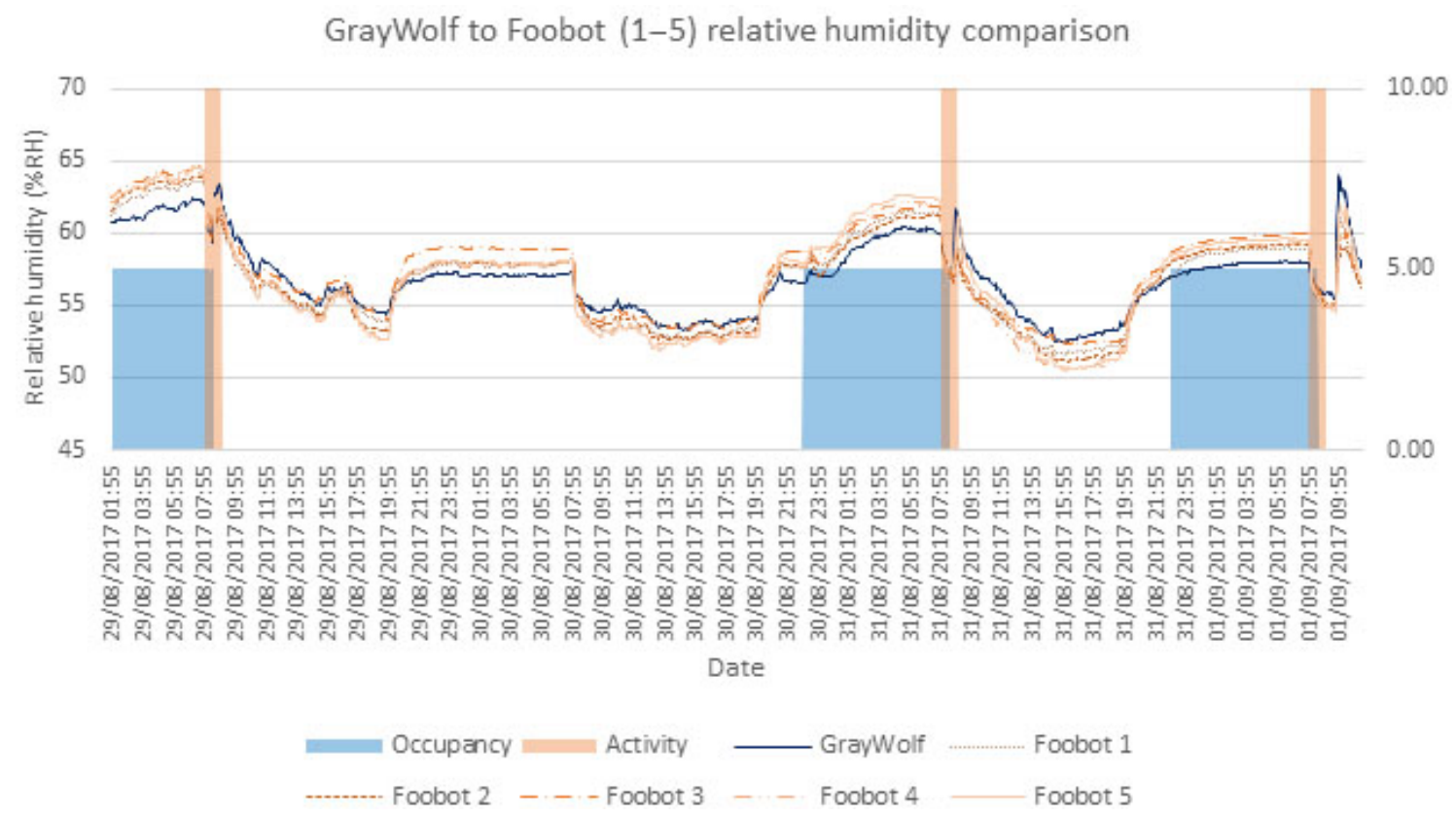

Figure 4. Relative humidity levels from 29 August to 1 September 2017 form the Foobot and GrayWolf instruments. (Activity describes the morning routine: showering, grooming, and changing.)

\subsection{Relationship between the GrayWolf and Foobot monitors}

\subsubsection{Total volatile organic compounds ( $\mathrm{VOOC}$ )}

The results from the $t \mathrm{VOC}$ measurements showed that Foobot FBT0002100 underestimated $t$ VOC concentrations. Figure 8 shows the relationship between the GrayWolf TG502 TVOC and Foobot FBT0002100 $t$ VOC concentrations from the calibration dataset used to generate a regression equation. The best fit produces an $R^{2}$ value of 0.697 and the equation generated by regression is

$$
\begin{aligned}
t \text { VOC GrayWolf } & =-1.56 e^{2}+4.5(t \text { VOC Foobot }) \\
& -0.02\left(t \text { VOC Foobot }{ }^{2}\right) \\
& +3.57 e^{-5}\left(t \text { VOC Foobot }^{3}\right)
\end{aligned}
$$

where $t \mathrm{VOC}$ is the concentration (ppb). Figure 9 shows the Bland-Altman plot comparing the GrayWolf $t \mathrm{VOC}$ measure- ments with that estimated from the Eq. (1) for the dataset from the five Foobot validations. It shows the mean between the GrayWolf and the Foobot $t$ VOC generated measurements $(-0.0148 \mathrm{ppb}$ with limits of agreement of -36.7935 to $36.7639 \mathrm{ppb}$ at a $95 \%$ confidence interval). A total of 80 $(3.26 \%)$ of the data points were outside of the limit of agreement (51 above the upper limit and 29 below the lower limit). This range is significantly lower than $300 \mathrm{ppb}$ (the World Health Organization, WHO, threshold for $t$ VOC; Koistinen et al., 2008). The plot shows that Foobot FBT0002100 underestimated the concentrations at high concentrations $(>300 \mathrm{ppb})$. A comparison between the $t$ VOC concentrations from the GrayWolf TG-503 TVOC and the Foobot $t \mathrm{VOC}$ generated showed indoor air quality information that has a very good agreement. The number of data points on which the $t \mathrm{VOC}$ concentration values exceeded the $300 \mathrm{ppb}$ is within $\pm 0.71 \%$ as observed in Table 6 . The agreement of the data points from the calibration and validation datasets 


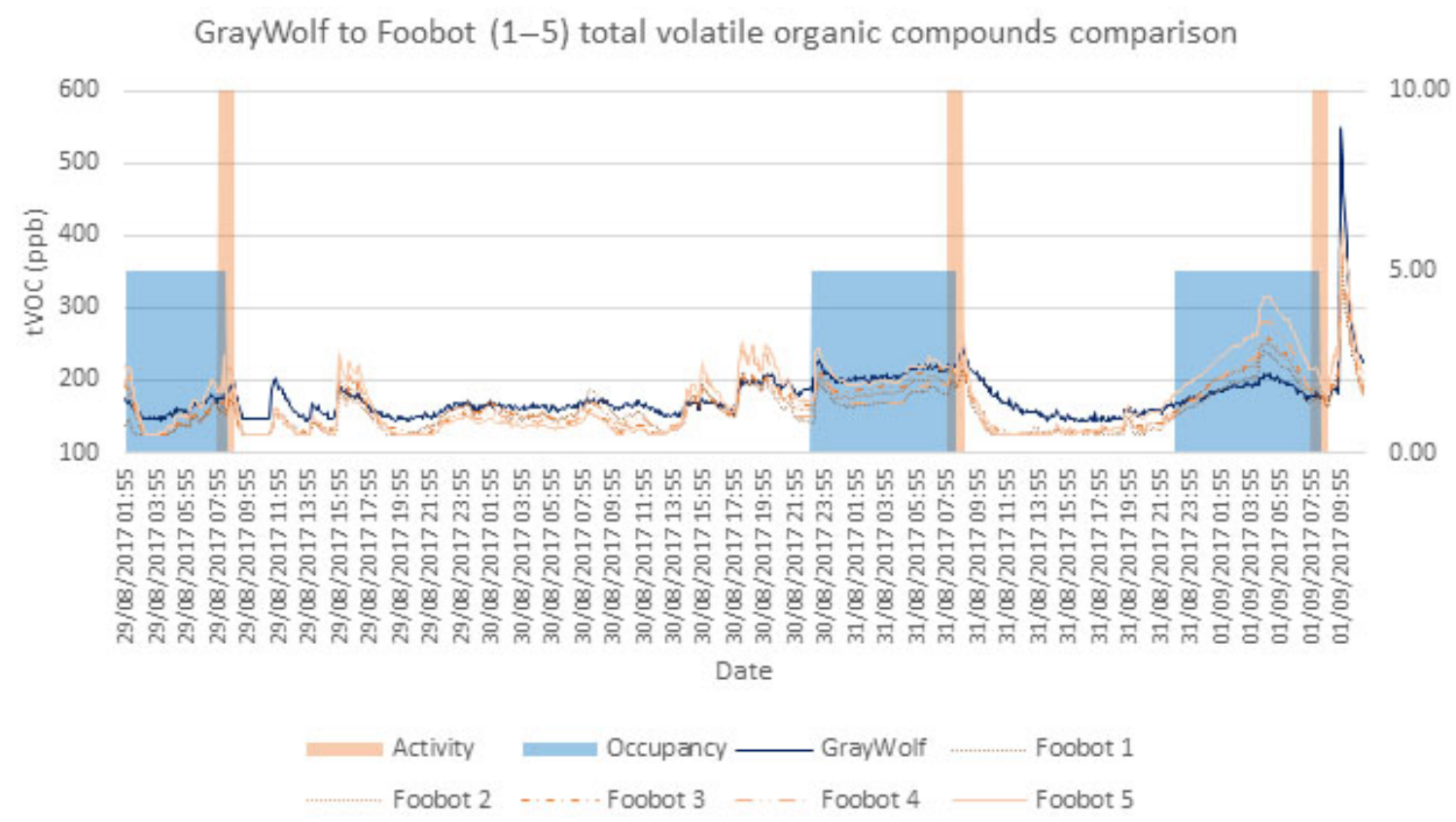

Figure 5. Total volatile organic compound levels from 29 August to 1 September 2017 form the Foobot and GrayWolf instruments. (Activity describes the morning routine: showering, grooming, and changing.)

Table 4. Summary statistics for $\mathrm{CO}_{2}$ calibration dataset divided by instruments.

\begin{tabular}{lrrrr}
\hline Instrument & $\begin{array}{r}\mathrm{CO}_{2} \text { mean } \\
(\mathrm{ppm})\end{array}$ & $\begin{array}{r}\mathrm{CO}_{2} \text { min. } \\
(\mathrm{ppm})\end{array}$ & $\begin{array}{r}\mathrm{CO}_{2} \text { max. } \\
(\mathrm{ppm})\end{array}$ & $\begin{array}{r}\% \text { time } \\
>1000 \mathrm{ppm}\end{array}$ \\
\hline GrayWolf IQ-410 & 727.2 & 451 & 1379 & $20.53 \%$ \\
Foobot FBT0002100 A & 572.2 & 450 & 1337 & $0.72 \%$ \\
Foobot FBT0002100 B & 581.6 & 450 & 1294 & $0.61 \%$ \\
Foobot FBT0002100 C & 591.5 & 450 & 1269 & $0.82 \%$ \\
Foobot FBT0002100 D & 597.7 & 450 & 1361 & $1.84 \%$ \\
Foobot FBT0002100 E & 628.1 & 450 & 1496 & $3.78 \%$ \\
\hline
\end{tabular}

were also corroborated. Both showed a very good agreement on the concentrations above $300 \mathrm{ppb}$ : on the calibration dataset, a $\kappa$ of 0.75 , and on the validation dataset, a $\kappa$ of 0.85 .

\subsubsection{Carbon dioxide $\left(\mathrm{CO}_{2}\right)$}

The results from the $\mathrm{CO}_{2}$ measurements showed a weak correlation as the $\mathrm{CO}_{2}$ concentrations were underestimated. Figure 10 shows the relationship between the GrayWolf IQ-410 and Foobot FBT0002100 $\mathrm{CO}_{2}$ concentrations from the calibration dataset used to generate the regression equation. The best fit produces an $R^{2}$ value of 0.180 and the equation generated by regression is

$$
\begin{aligned}
\mathrm{CO}_{2} \text { GrayWolf } & =-1.39 e^{3}+7.08\left(\mathrm{CO}_{2} \text { Foobot }\right) \\
& -7.15 e^{-3}\left(\mathrm{CO}_{2} \text { Foobot }^{2}\right) \\
& +2.29 e^{-6}\left(\mathrm{CO}_{2} \text { Foobot }^{3}\right)
\end{aligned}
$$

where $\mathrm{CO}_{2}$ is the concentration in ppb. Figure 11 shows the Bland-Altman plot comparing the GrayWolf $\mathrm{CO}_{2}$ measurements with those estimated from the Eq. (2) to the five Foobot validation datasets. It shows the mean difference between the GrayWolf and the Foobot $\mathrm{CO}_{2}$ generated measurements (4.1149 with limits of agreement of -457.453 to $465.683 \mathrm{ppm}$ at a $95 \%$ confidence interval). A total of 152 $(6.21 \%)$ of the data points were outside of the limits of agreement ( 152 above the upper limit). This range is almost equal to the $1000 \mathrm{ppm}$ (the ASHRAE threshold for $\mathrm{CO}_{2}$ ASHRAE, 2007). A comparison between the $\mathrm{CO}_{2}$ concentrations and the Foobot $\mathrm{CO}_{2}$ generated to produce information about the ventilation rates showed that there was a poor agreement between them. The number of data points on which the $\mathrm{CO}_{2}$ concentration values exceed the $1000 \mathrm{ppm}$ was significantly different from the GrayWolf instruments to those generated by the Eq. (2) as shown in Table 7. The agreement of the data points from the calibration and validation datasets was also 


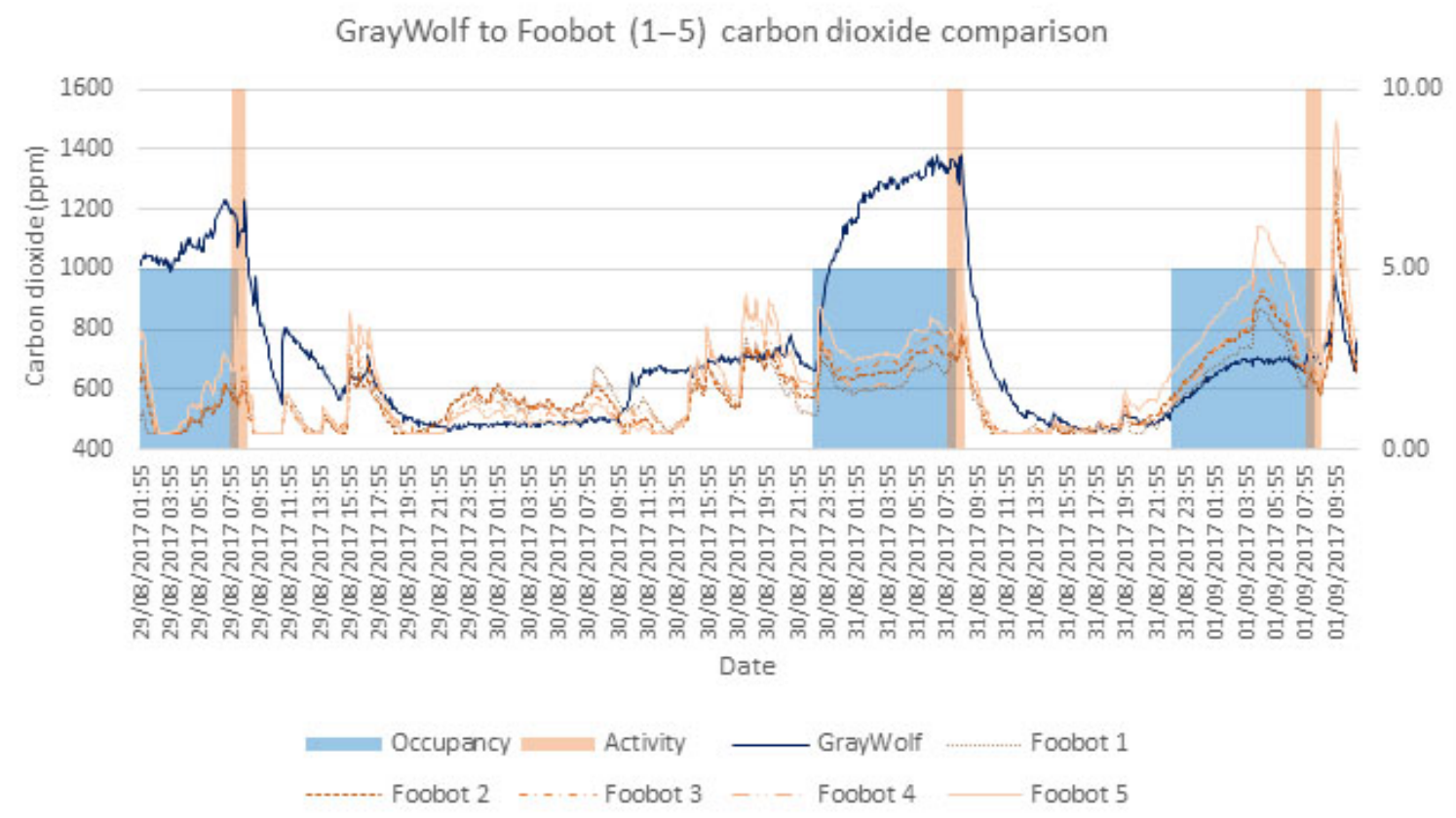

Figure 6. Carbon dioxide levels from 29 August to 1 September 2017 form the Foobot and GrayWolf instruments. (Activity describes the morning routine: showering, grooming, and changing.)

Table 5. Summary statistics for $\mathrm{PM}_{2.5}$ calibration dataset divided by instruments.

\begin{tabular}{lrrrr}
\hline Instrument & $\begin{array}{r}\mathrm{PM}_{2.5} \text { mean } \\
\left(\mu \mathrm{g} \mathrm{m}^{-3}\right)\end{array}$ & $\begin{array}{r}\mathrm{PM}_{2.5} \mathrm{~min} . \\
\left(\mu \mathrm{g} \mathrm{m}^{-3}\right)\end{array}$ & $\begin{array}{r}\mathrm{PM}_{2.5} \mathrm{max} . \\
\left(\mu \mathrm{g} \mathrm{m}^{-3}\right)\end{array}$ & $\begin{array}{r}\% \text { time } \\
>25 \mu \mathrm{g} \mathrm{m}^{-3}\end{array}$ \\
\hline GrayWolf PC-3016A & 6.8438 & 3.54 & 35.78 & $0.82 \%$ \\
Foobot FBT0002100 A & 8.3273 & 3.96 & 35.7 & $1.43 \%$ \\
Foobot FBT0002100 B & 8.3288 & 1 & 44.24 & $1.43 \%$ \\
Foobot FBT0002100 C & 8.3243 & 3.18 & 39.06 & $1.43 \%$ \\
Foobot FBT0002100 D & 8.3311 & 3.48 & 36.14 & $1.23 \%$ \\
Foobot FBT0002100 E & 8.3224 & 2.99 & 42.55 & $1.33 \%$ \\
\hline
\end{tabular}

corroborated. Both showed a complete disagreement on the concentrations above $1000 \mathrm{ppm}$ : on the calibration dataset, a $\kappa$ of 0 , and on the validation dataset, a $\kappa$ of 0 .

\subsubsection{Particulate matter $2.5 \mu \mathrm{m}\left(\mathrm{PM}_{2.5}\right)$}

The results from the $\mathrm{PM}_{2.5}$ measurements showed that Foobot was overestimating particle matter concentrations. Figure 12 shows the relationship between the GrayWolf PC3016A and Foobot FBT0002100 $\mathrm{PM}_{2.5}$ concentrations from the calibration dataset used to generate the regression equation. The best fit produces an $R^{2}$ value of 0.887 and the equation generated by regression is

$$
\begin{aligned}
\mathrm{PM}_{2.5} \text { GrayWolf } & =0.49+0.79\left(\mathrm{PM}_{2.5} \text { Foobot }\right) \\
& +3.76 e^{-3}\left(\mathrm{PM}_{2.5} \text { Foobot }^{2}\right),
\end{aligned}
$$

where $\mathrm{PM}_{2.5}$ is the mass concentration $\left(\mu \mathrm{g} \mathrm{m}^{-3}\right)$. Figure 13 shows the Bland-Altman plot comparing the GrayWolf
$\mathrm{PM}_{2.5}$ measurements with those estimated from Eq. (3) to the five Foobot validation dataset. It shows the mean difference between the GrayWolf and the Foobot $t$ VOC generated measurements $(-0.0137$ with limits of agreement of -2.32 to $2.29 \mu \mathrm{g} \mathrm{m}^{-3}$ at a $95 \%$ confidence interval). A total of $100(4.08 \%)$ of the data points were outside of the limit of agreement ( 58 above the upper limit and 42 below the lower limit). This range is significantly lower than $25 \mu \mathrm{g} \mathrm{m}^{-3}$ (the WHO threshold for $\mathrm{PM}_{2.5}$; WHO, 2000). A comparison between the $\mathrm{PM}_{2.5}$ concentrations and the Foobot $\mathrm{PM}_{2.5}$ generated to produce indoor air quality information showed that there was a very good agreement between them. The number of data points on which the $\mathrm{PM}_{2.5}$ concentration values exceeded the $25 \mu \mathrm{g} \mathrm{m}^{-3}$ was within $\pm 0.21 \%$ as observed in Table 8 . The agreement of the data points from the calibration and validation datasets was also corroborated. Both showed a very good agreement on the concentrations above $25 \mu \mathrm{g} \mathrm{m}^{-3}$ : 


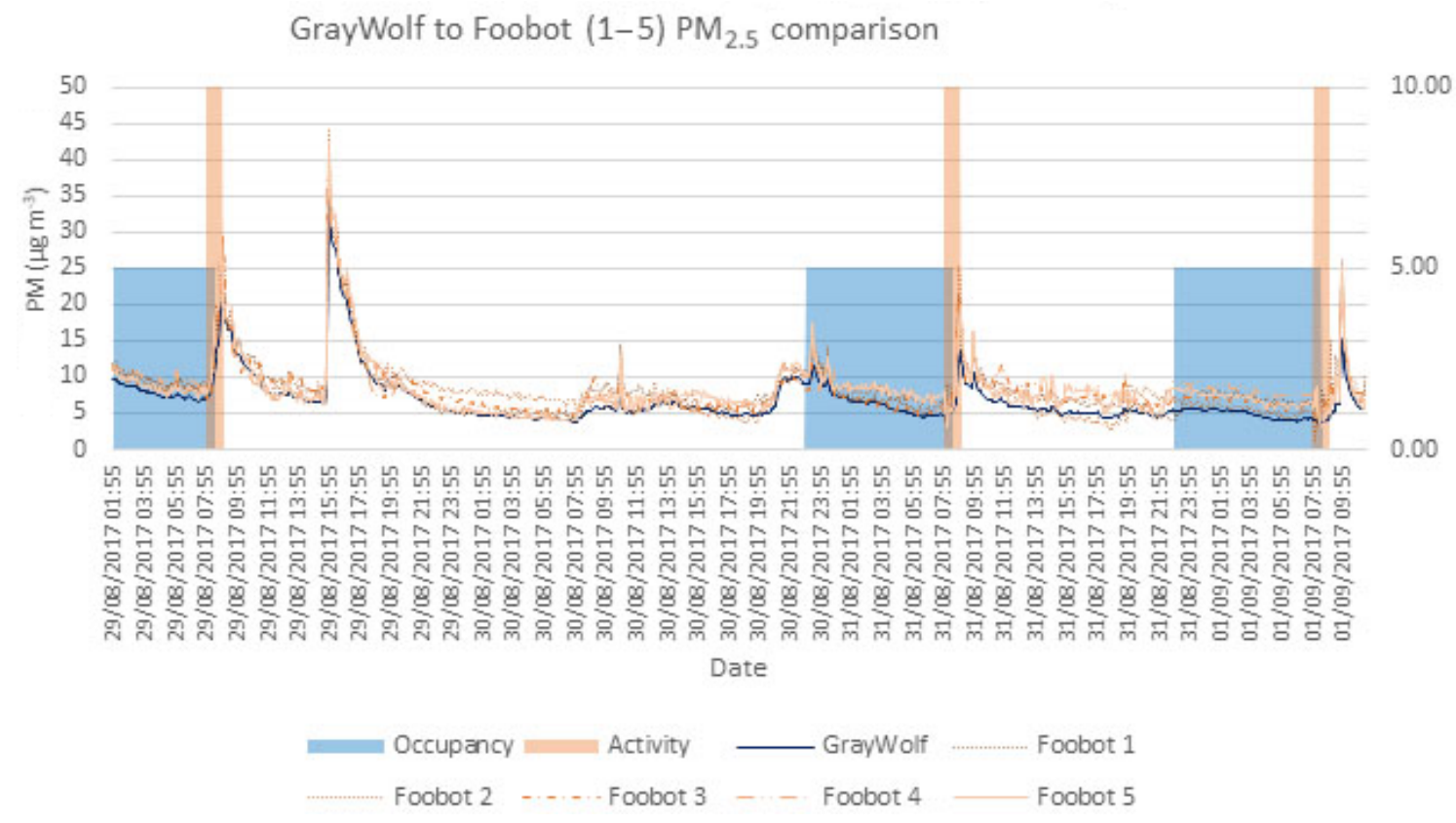

Figure 7. $\mathrm{PM}_{2.5}$ levels from 29 August to 1 September 2017 form the Foobot and GrayWolf instruments. (Activity describes the morning routine: showering, grooming, and changing.)

Table 6. Summary statistics for the generated $t$ VOC from the validation dataset divided by instruments.

\begin{tabular}{lrrrr}
\hline Instrument & $\begin{array}{r}t \text { VOC mean } \\
(\mathrm{ppb})\end{array}$ & $\begin{array}{r}t \text { VOC min. } \\
(\mathrm{ppb})\end{array}$ & $\begin{array}{r}t \text { VOC max. } \\
(\mathrm{ppb})\end{array}$ & $\begin{array}{r}\% \text { time } \\
>300 \mathrm{ppb}\end{array}$ \\
\hline GrayWolf TG-502 TVOC & 176.4 & 143 & 549 & $0.82 \%$ \\
Generated Foobot A & 172.97 & 149.9 & 456.59 & $0.31 \%$ \\
Generated Foobot B & 174.09 & 149.9 & 416.58 & $0.41 \%$ \\
Generated Foobot C & 175.6 & 149.9 & 394.51 & $0.41 \%$ \\
Generated Foobot D & 176.88 & 149.9 & 483.35 & $0.61 \%$ \\
Generated Foobot E & 182.53 & 149.9 & 658.15 & $1.53 \%$ \\
\hline
\end{tabular}

on the calibration dataset, a $\kappa$ of 0.9 , and on the validation dataset, a $\kappa$ of 0.85 .

\section{Discussion}

Measurements of temporal and spatial changes of indoor contaminant concentrations are vital to gain an in-depth understanding of pollutant characteristics, particularly in dynamic, spatially variable environments such as the home. While scientific instruments can provide high temporal resolution of indoor pollutants such as $\mathrm{PM}_{2.5}, \mathrm{PM}_{10}$, and $t \mathrm{VOCs}$, the cost and complexity of these instruments renders monitoring of spatial and temporal changes on a large-scale prohibitively difficult.

This work tries to find a more affordable and suitable instrument to provide indoor air quality information, which may also enable simultaneous monitoring of different rooms within the same home. However, it might also facilitate more extensive indoor air quality monitoring projects looking to characterise pollution and identify potential health risks in indoor building environments with much larger and more statistically significant datasets. A previous experiment in a controlled chamber showed that the monitor could be used to provide mass concentrations of $\mathrm{PM}_{2.5}$ (Sousan et al., 2017), but this is the first study to evaluate the accuracy of all measurements (temperature, relative humidity, $t \mathrm{VOC}, \mathrm{CO}_{2}$, and $\mathrm{PM}_{2.5}$ ) of the Foobot FBT0002100 in real-life residential settings, producing more than 4800 data points.

Calibration equations for the site were calculated as suggested by Sousan et al. (2017). The equations generated may be influenced by domestic pollution (i.e. pollutants from paint, cleaning, and personal care products; household dust, outdoor air, and cooking fumes). The density and features of such contaminants will be different depending on the household. Hence, the response of the instruments like GrayWolf PC-3016A, TG-502 TVOC, IQ-410, and Foobot 
Table 7. Summary statistics for the generated $\mathrm{CO}_{2}$ from the validation dataset divided by instruments.

\begin{tabular}{lrrrr}
\hline Instrument & $\begin{array}{r}\mathrm{CO}_{2} \text { mean } \\
(\mathrm{ppm})\end{array}$ & $\begin{array}{r}\mathrm{CO}_{2} \text { min. } \\
(\mathrm{ppm})\end{array}$ & $\begin{array}{r}\mathrm{CO}_{2} \text { max. } \\
(\mathrm{ppm})\end{array}$ & $\begin{array}{r}\% \text { time } \\
>1000 \mathrm{ppm}\end{array}$ \\
\hline GrayWolf TG-502 TVOC & 727.24 & 451.00 & 1379.00 & $20.53 \%$ \\
Generated Foobot A & 715.86 & 556.80 & 870.66 & $0.00 \%$ \\
Generated Foobot B & 720.05 & 556.80 & 870.68 & $0.00 \%$ \\
Generated Foobot C & 725.15 & 556.80 & 870.68 & $0.00 \%$ \\
Generated Foobot D & 725.05 & 556.80 & 870.69 & $0.00 \%$ \\
Generated Foobot E & 729.51 & 556.80 & 870.69 & $0.00 \%$ \\
\hline
\end{tabular}

Table 8. Summary statistics for the generated $\mathrm{PM}_{2.5}$ from the validation dataset divided by instruments.

\begin{tabular}{lrrrr}
\hline Instrument & $\begin{array}{r}\mathrm{PM}_{2.5} \text { mean } \\
\left(\mu \mathrm{g} \mathrm{m}^{-3}\right)\end{array}$ & $\begin{array}{r}\mathrm{PM}_{2.5} \text { min. } \\
\left(\mu \mathrm{g} \mathrm{m}^{-3}\right)\end{array}$ & $\begin{array}{r}\mathrm{PM}_{2.5} \text { max. } \\
\left(\mu \mathrm{g} \mathrm{m}^{-3}\right)\end{array}$ & $\begin{array}{r}\% \text { time } \\
>25 \mu \mathrm{g} \mathrm{m}^{-3}\end{array}$ \\
\hline GrayWolf PC-3016A & 5.3604 & 1.87 & 34.52 & $0.82 \%$ \\
Generated Foobot A & 6.8484 & 3.42 & 31.18 & $0.72 \%$ \\
Generated Foobot B & 6.8611 & 1.22 & 39.95 & $0.82 \%$ \\
Generated Foobot C & 6.8479 & 2.83 & 34.57 & $0.72 \%$ \\
Generated Foobot D & 6.8442 & 3.06 & 31.62 & $0.61 \%$ \\
Generated Foobot E & 6.8552 & 2.7 & 38.18 & $0.72 \%$ \\
\hline
\end{tabular}

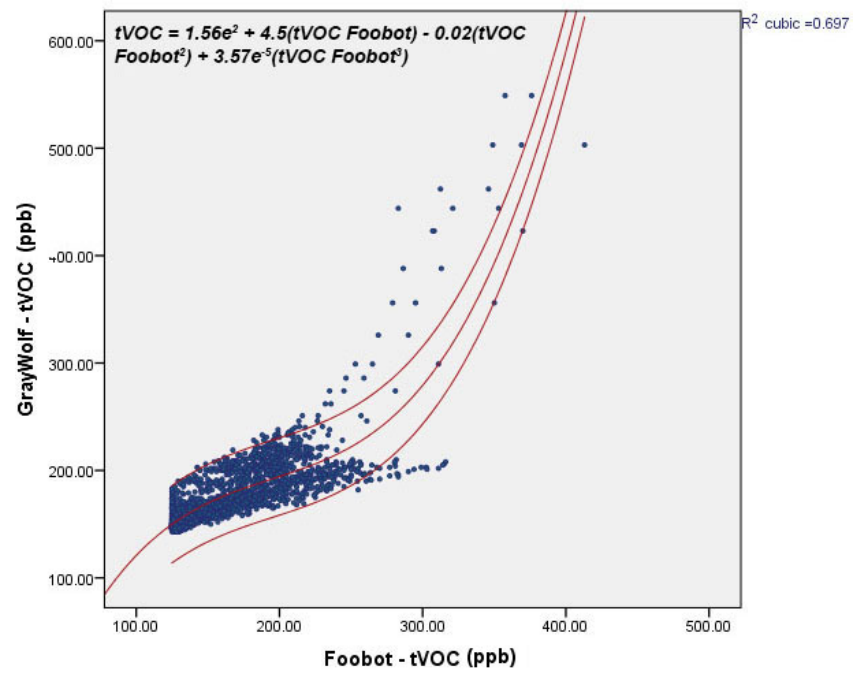

Figure 8. Scatter plot of the $5 \mathrm{~min} t \mathrm{VOC}$ concentration measured using the Foobot FBT0002100 and the GrayWolf TG-502 TVOC from the calibration dataset.

FBT0002100 may vary in real-life homes, depending on this and other factors such as monitor location, temperature, and humidity. Therefore, to provide the most accurate measurements, an individual calibration equation could be provided for each Foobot FBT0002100. This, however, may not be possible in large-scale and remotely deployable projects. A better alternative for large-scale projects may be to produce a calibration equation for a large set of monitors for each setting (i.e. bedroom, kitchen, and living room). Then, in order

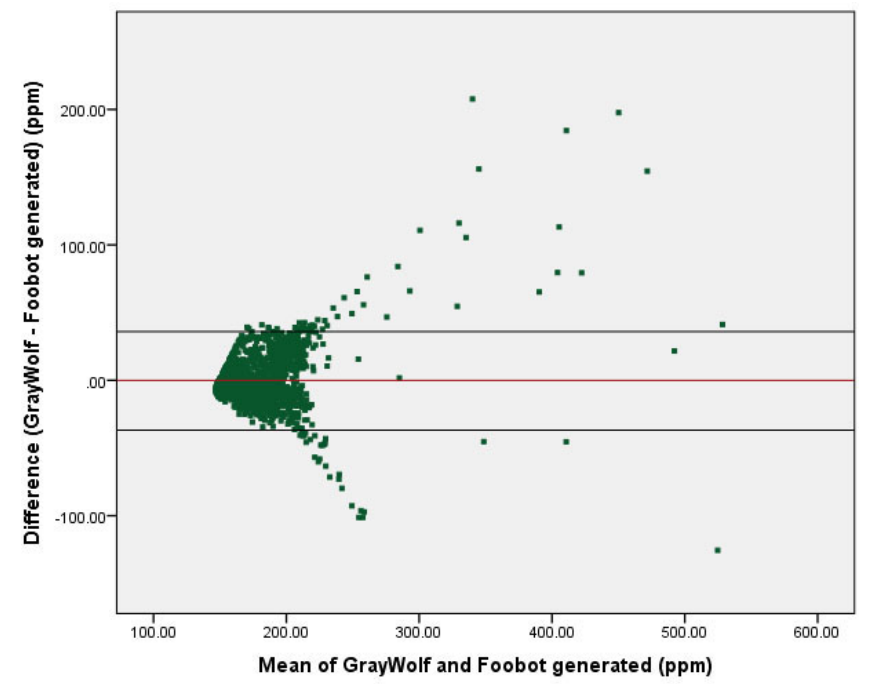

Figure 9. Bland-Altman plot of the agreement between the GrayWolf TG-502 TVOC and the Foobot-generated $t$ VOC concentrations.

to reduce the bias of inter-Foobot differences, use three monitors within the same space and use the mean from the monitors in each room to provide a more robust measurement. This alternative provides not only higher accuracy than the application of a calibration equation, but the redundancy of the acquired data from several monitors also provides higher confidence and robustness to the dataset.

The validation results showed that there was a very good agreement between the GrayWolf PC-3016A/TG-502 


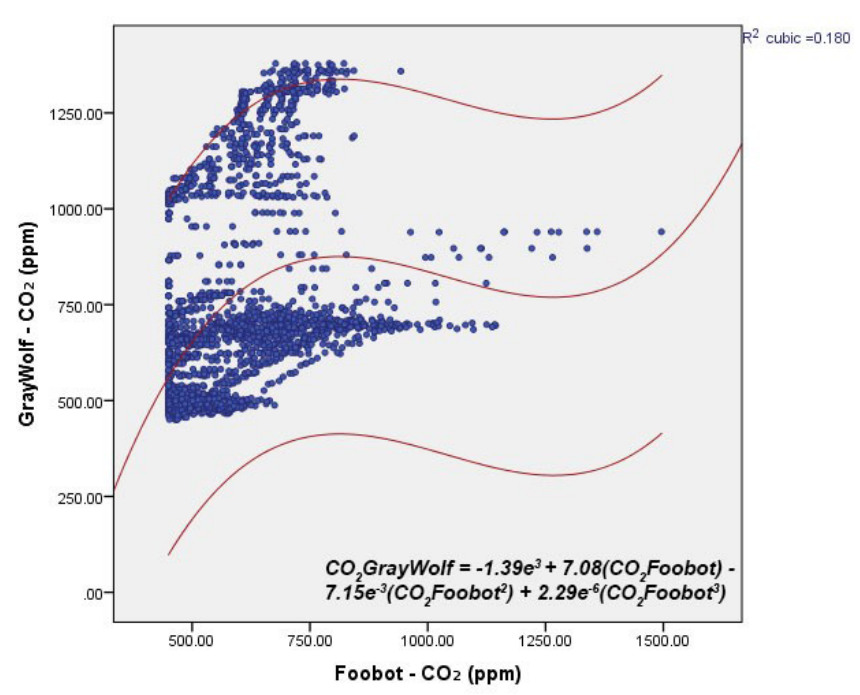

Figure 10. Scatter plot of the 5 min $\mathrm{CO}_{2}$ concentration measured using the Foobot FBT0002100 and the GrayWolf IQ-410 from the calibration dataset.

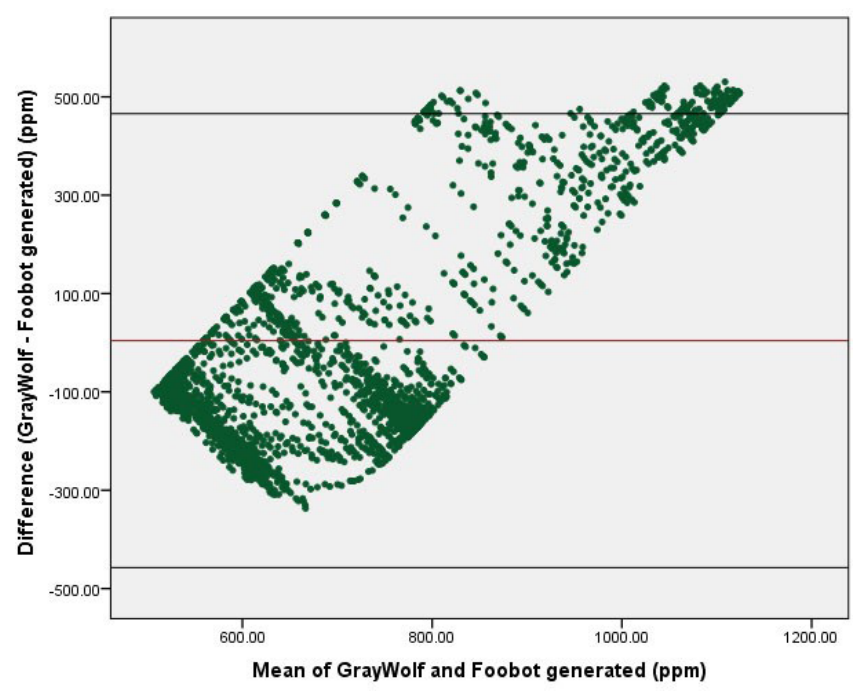

Figure 11. Bland-Altman plot of the agreement between the GrayWolf IQ-410 and the Foobot-generated $\mathrm{CO}_{2}$ concentrations.

TVOC/IQ-410 and the Foobot FBT0002100 with regard to temperature and humidity, and to $t \mathrm{VOC}$ and $\mathrm{PM}_{2.5}$ when the regression equations were applied. The $\mathrm{CO}_{2}$ concentration levels were not accurate as the Foobot FBT0002100 instrument does not possess a real $\mathrm{CO}_{2}$ sensor, but instead provides a $\mathrm{CO}_{2}$ equivalent from the $t \mathrm{VOC}$ levels as an indication. Differences between $\mathrm{CO}_{2}$ levels from the GrayWolf IQ-410 and the Foobot are clear in Fig. 6. While the GrayWolf IQ-410 uses non-dispersive infrared spectroscopy technology to determine $\mathrm{CO}_{2}$ concentrations, the Foobot uses an algorithm to convert $t \mathrm{VOC}$ to $\mathrm{CO}_{2}$ equivalents, providing misleading measurements. The differences in the mea-

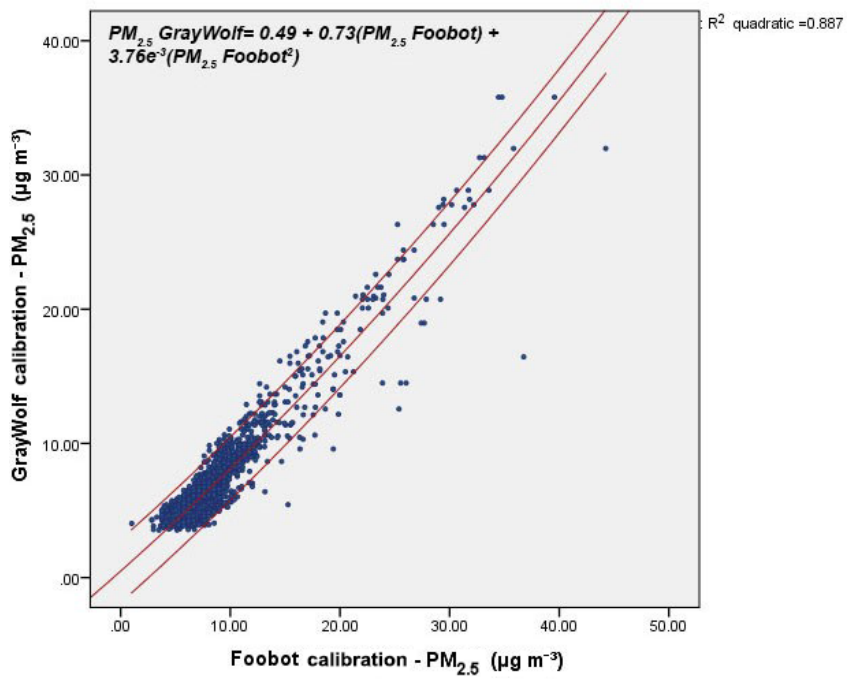

Figure 12. Scatter plot of the 5 min $\mathrm{PM}_{2.5}$ concentration measured using the Foobot FBT0002100 and the GrayWolf PC-3016A from the calibration dataset.

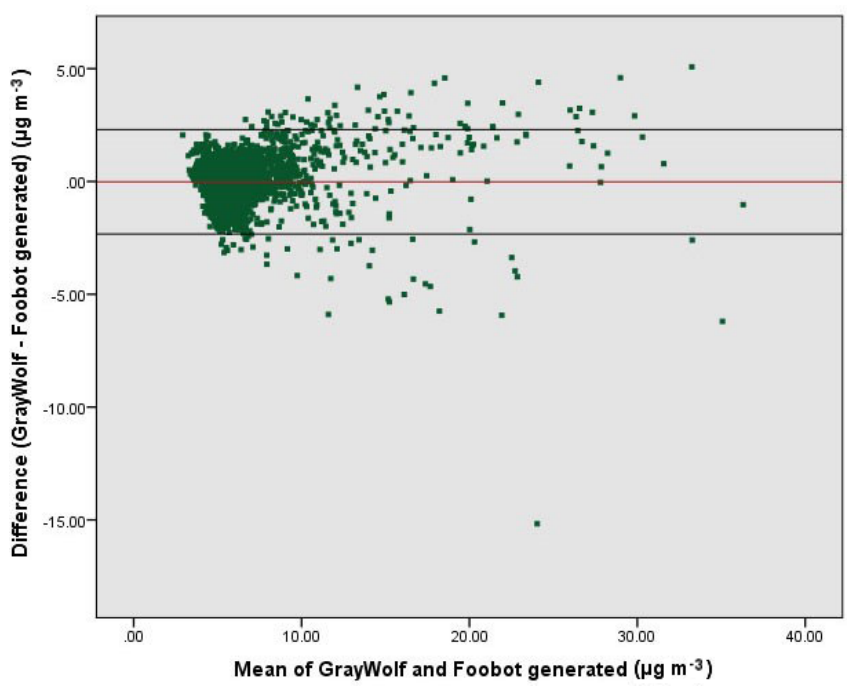

Figure 13. Bland-Altman plot of the agreement between the GrayWolf PC-3016A and the Foobot-generated $\mathrm{PM}_{2.5}$ concentrations.

surements were expected since $\mathrm{CO}_{2}$ and $t \mathrm{VOC}$ are different chemicals and have different sources and compositions. $\mathrm{CO}_{2}$ concentrations in indoor environments have long been used as an indicator of ventilation (ASHRAE, 2007). Levels of $\mathrm{CO}_{2}$ correlate to human activities and occupancy (Porteous, 2011) but are not related to sources of pollution such as offgassing from building materials or furniture (Brown et al., 1994) as it is the case for $t$ VOC. The implementation of the algorithm to predict $\mathrm{CO}_{2}$ is relatively new, and the theory behind it debates that $t$ VOC can be correlated proportionally to $\mathrm{CO}_{2}$ production providing $\mathrm{CO}_{2}$ - and $t \mathrm{VOC}$-related events at the same time (Herberger et al., 2010). In other words, 
(a)

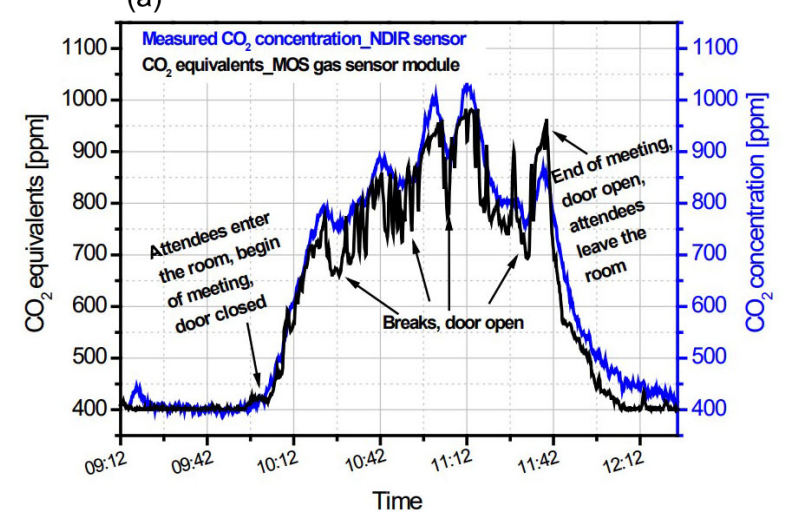

(b)

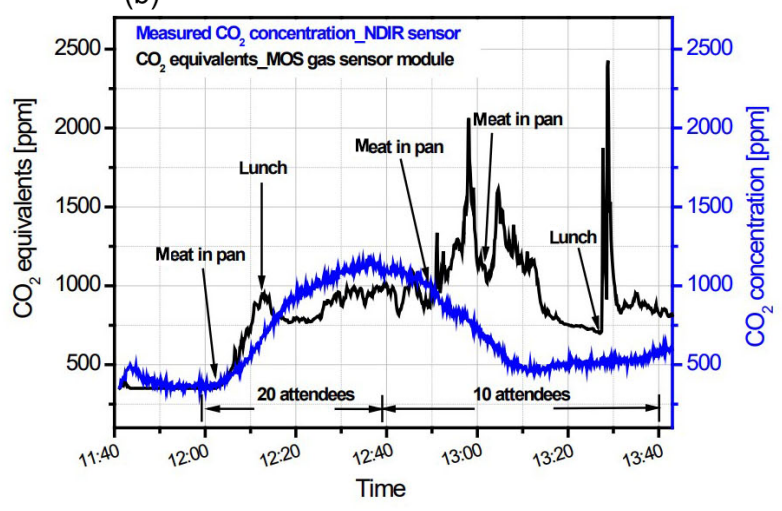

Figure 14. The graphics compares the real $\mathrm{CO}_{2}$ measurements vs. $\mathrm{CO}_{2}$ equivalents from $t \mathrm{VOC}$ of a previous study. Real $\mathrm{CO}_{2}$ (in blue) and $\mathrm{CO}_{2}$ equivalent from $t$ VOC (in black) in a meeting room (a) and kitchen (b). Source: Ulmer and Herberger (2012).

the algorithm attempts to relate $t \mathrm{VOC}$ to $\mathrm{CO}_{2}$ concentrations in indoor spaces where no human activity takes place (U1mer and Herberger, 2012). Most of the studies to correlate $\mathrm{CO}_{2}$ equivalents to $t \mathrm{VOC}$ have been carried out in schools, offices, meeting rooms, and home environments. For example, Fig. 14 (Ulmer and Herberger, 2012) compares the $\mathrm{CO}_{2}$ equivalents calculated from $t \mathrm{VOC}$ to $\mathrm{CO}_{2}$; the left graphic shows a strong correlation in a meeting room, whereas the right graphic show signals that can be attributed to $t \mathrm{VOC}$ but differ from $\mathrm{CO}_{2}$. Implications of this approach may include misleading $\mathrm{CO}_{2}$ readings that may confuse many new to the IAQ industry; however, it provides the possibility to add the sensor output to ventilation standards (Herberger et al., 2010) and implement it for ventilation systems reducing the energy consumption compared to time-scheduled ventilation (Ulmer and Herberger, 2012). However, this approach has only recently been developed and additional development of IAQ modules is needed (Ulmer and Herberger, 2012), especially in residential environments. AirBoxLab opted for the iAQ-CORE-C sensor to provide $t$ VOC concentrations and an idea of $\mathrm{CO}_{2}$ instead of real $\mathrm{CO}_{2}$ measurements for two main reasons. First, they believed that $t \mathrm{VOC}$ measurements are more important to evaluate IAQ as the health impacts of higher levels of $t$ VOC are usually more severe than those from $\mathrm{CO}_{2}$; second, the additional cost for the $\mathrm{CO}_{2}$ sensor may increase the price for the Foobot (personal communication, Jacques Touillon, 2016).

About $3.2 \%$ of the $t \mathrm{VOC}$ measurements and $4.1 \%$ of $\mathrm{PM}_{2.5}$ were outside of the limits of agreement when an upper and lower bound of 1.96 standard deviation (SD) of the difference was applied. There is, however, a concern as to whether or not the $1.96 \mathrm{SD}$ limits are appropriate to assess the impact of pollution on human health (Bland and Altman, 2010). For this reason, the $1.96 \mathrm{SD}$ was transformed into pollution concentrations to ensure these bounds were either the same as or lower in range than those thresholds set by the WHO, which resulted in tighter ranges. The 1.96 SD for
$\mathrm{PM}_{2.5}$ resulted in a range from -2.3245 to $2.2971 \mu \mathrm{g} \mathrm{m}^{-3}$ $\left( \pm 2.2932 \mu \mathrm{g} \mathrm{m}^{-3}\right.$ from the mean) and from -36.7935 to $35.9668 \mathrm{ppb}$ for $t$ VOC $( \pm 36.5920 \mathrm{ppb}$ from the mean). The examination of the instruments to produce indoor air quality information reinforced this conclusion, as the quantitative information provided by the different instruments demonstrated high agreement. Variability between the percentage of time above threshold values determined using data from the Foobot and the GrayWolf monitors was generally small and was considered to be unlikely to produce major changes in indoor air quality assessments.

The findings show that the Foobot FBT0002100 provided sufficiently accurate results for an evaluation of the IAQ in occupied dwellings and that the information provided could identify trends and exposures above thresholds within a small margin of error. As the Foobot does not make any noise or emit light, it could be used to perform simultaneous measurements of the indoor environment inside homes, including sensitive spaces such as bedrooms. This should minimise changes in participants' behaviour in response to their awareness of being observed, minimising the Hawthorne effect (Landsberger and Ithaca, 1958) and the risk of occupants disconnecting the monitors. Moreover, the cost, size, mobility, and easy deployment of the Foobot FBT0002100 combined with its accuracy make it a useful tool to evaluate occupant pollutant exposure in research and large-scale monitoring campaigns which could collect high-density temporal and spatial data on indoor pollutant concentrations in a wide range of households at local, regional, and national levels. This information could be used to acquire more comprehensive information on indoor pollutant concentrations to better understand temporal and spatial changes and pollutantactivity relationships in the home.

This study suffers from some identifiable limitations. Firstly, there was no comparison or control group in an environmental chamber. Environmental chamber experiments would include the use of calibration gases and aerosols, al- 
lowing comparison with a wider range of highly accurate instruments. However, the purpose of this study was to evaluate the intended purpose of low-cost consumer monitors in field conditions, as an experiment in a controlled environment has been published already. Secondly, it was assumed that GrayWolf PC-3016A/TG-502 TVOC/IQ-410 provided accurate temperature, humidity, $\mathrm{CO}_{2}, \mathrm{CO}$, VOCs, and $\mathrm{PM}_{2.5}$ concentrations. While the devices were tested and calibrated by the manufacturer a month before this study, this still represents a potential error. Thirdly, we assumed that the monitors were left in place throughout sampling. We asked the participants not to handle the devices, but the light and noise produced by the GrayWolf instruments might cause occupants to relocate it; however, there was no evidence that the monitors were relocated.

Further work will examine the variability of Foobot devices and explore the influence of temperature and humidity on their response to air pollutants, especially to $\mathrm{PM}_{2.5}$. Other research may study the use of low-cost monitoring devices as IAQ educational tools for home users, looking at the behavioural changes towards IAQ.

\section{Conclusions}

Recently there has been an increase in interest in understanding the effects of indoor air pollution on human health. Traditional analytical instruments are impractical, costly, and often their accuracy is much higher than needed to assess indoor pollution levels. Several low-cost consumer monitors provide information about the quality of indoor air. Therefore, it is considered useful to assess their accuracy in environmental chamber and field experiments to evaluate their utility and accuracy. The Foobot FBT0002100 offers a relatively low-cost and straightforward solution to deliver households' air quality information that may be used to gather large-scale household IAQ data and also to motivate occupants to reduce the potential harm of indoor pollution. It also has the potential to examine the impact of increased occupant awareness of IAQ on ventilation and pollution-related behaviours.

The Foobot FBT0002100 was found to have a significant agreement with the GrayWolf instruments, for temperature $\left(r_{\mathrm{s}}=0.832-0.871\right)$, relative humidity $\left(r_{\mathrm{s}}=0.935-\right.$ $0.948), t$ VOC $\left(r_{\mathrm{s}}=0.827-0.869\right)$, and $\mathrm{PM}_{2.5} \quad\left(r_{\mathrm{s}}=0.787-\right.$ $0.866)$ data. The temperature was found to be underestimated by $2.59^{\circ} \mathrm{C}$. The calibration equations produced for $t \mathrm{VOC}$ $\left(R^{2}=0.697\right)$ and $\mathrm{PM}_{2.5}\left(R^{2}=0.887\right)$ reduced variability between the monitors and improved their accuracy when compared to the GrayWolf instruments. Foobot's lack of a specific $\mathrm{CO}_{2}$ sensor estimated misleading concentrations. However, results showed that this does not impact the accuracy of the other sensors. Therefore, Foobot can be used for studies where ventilation is not an indispensable metric for the research, but it can be complemented by another $\mathrm{CO}_{2}$ sensor.
The findings suggest that low-cost monitors, such as the Foobot FBT0002100, have the potential to identify high pollutant exposures and to provide high-density, reliable, temporal data at high granularity. Its characteristics, such as remote data retrieval as well as its accuracy, make Foobot a useful tool to evaluate occupant pollutant exposure at a large-scale and longer timescales in occupied dwellings, compared to current approaches. However, as discussed, the use of several units within the same space and with a calibration equation may improve the overall performance of the monitor.

Data availability. This study is part of a $\mathrm{PhD}$ investigation. Access to the data may be possible upon written request to the main author.

Competing interests. The manufacturer of the air quality monitor tested in 2016/17 (Foobot) subsequently offered discounted devices to enable further research. This offered was accepted only after the review of the device was concluded in order to maintain authorial independence.

Acknowledgements. We would like to thank all those who took part in this study, especially Janice Foster and Anna Poston for providing technical support for the use of the monitoring devices. Thanks are given to Adam Hotson and Ian Faller, who offered useful editing and proofreading of an earlier version of this paper. CONACyT partially funded this study as part of a $\mathrm{PhD}$ scholarship to the main author.

Edited by: Rosario Morello

Reviewed by: three anonymous referees

\section{References}

Air Quality Expert Group: Methods for monitoring particulate concentrations, in: Particulate Matter in the United Kingdom, 1st Edn., London, Defra, 125-154, 2005.

Ali, A. S., Zanzinger, Z., Debose, D., and Stephens, B.: Open Source Building Science Sensors (OSBSS): A lowcost Arduino-based platform for long-term indoor environmental data collection, Build. Environ., 100, 114-126, https://doi.org/10.1016/j.buildenv.2016.02.010, 2016.

AMS: iQA-CORE datasheet, AMS, available at: http://ams.com/ eng/Products/Environmental-Sensors/Air-Quality-Sensors/ iAQ-core-C (last access: 29 August 2017), 2015.

An, M. S. and Kang, D.: Development of Weather Condition Observation System for Wind Turbine Based on Integrated Sensor Module Gateway, in: Advanced Science and Technology Letters, 51, 238-241, 2014.

ASHRAE: ASHRAE standard 62.1-2007 Ventilation for Acceptable Indoor Air Quality, Atlanta, GA, 2007.

ASTM: ASTM Volume 11.07 Air Quality - D7297-14, Standard Practice for Evaluating Residential Indoor Air Quality, 2014.

Berry, R., Crump, D., Brown, V., and Coward, S. K. D.: Indoor air quality in homes, part 1, 1st Edn., Watford, BRE press, 1996. 
Bland, J. M. and Altman, D. G.: Statistical methods for assessing agreement between two methods of clinical measurement, Int. J. Nurs. Stud. 47, 931-936, https://doi.org/10.1016/j.ijnurstu.2009.10.001, 2010.

Boyd, D. R.: Dodging the Toxic Bullet, how to Protect Yourself from Everyday Environmental Health Hazards, 1st Edn., Vancouver, Greystone Books, 2010.

Brown, N.: Technical article - New small, low-power MOX VOC sensors: how might they be used for indoor air quality monitoring?, AMS, avaliable at: http://ams.com/eng/Support/ Technical-Papers/VOCs-and-IAQ, last access: 29 August 2017.

Brown, S. K., Sim, M. R., Abramson, M. J., and Gray, C. N.: Concentrations of volatile organic compounds in indoor air-a review, Indoor Air, 4, 123-134, 1994.

Carrer, P., Fanetti, A. C., Forastiere, F., Holcatova, I., Molhave, L., Sundell, J., Viegi, G., and Simoni, M.: WP1 Technical Report, Health Effects, Final report, EnVIE Co-ordination Action on Indoor Air Quality and Health Effects, 2008.

Chan, C. S., Ostertag, M. H., Akyürek, A. S., and Šimunić Rosing, T.: Context-aware system design, in: Micro- and Nanotechnology Sensors, Systems, and Applications IX, edited by: George, T., Achyut, K., Dutta, M., and Sailf, I., Anaheim, US, 9-13 April 2017, paper no. 101940B, 1-17, Washington, SPIE, https://doi.org/10.1117/12.2263232, 2017.

Chou, J.: Chapter 1 - Introduction, in: Hazardous gas monitors: A Practical Guide to Selection, Operation and Applications, 1st Edn., New York, McGraw-Hill Professional, 1-24, 2000.

Crump, D., Raw, G. J., Upton, S., Scivyer, C., Hunter, C., and Hartless, R.: A protocol for the assessment of indoor air quality in homes and office buildings, 1st Edn., London:, BRE bookshop, 2002.

Ferdoush, S. and Li, X.: Wireless sensor network system design using Raspberry $\mathrm{Pi}$ and Arduino for environmental monitoring applications, Procedia Comput. Sci., 34, 103-110, https://doi.org/10.1016/j.procs.2014.07.059, 2014.

Gee, I. L., Semple, S., Watson, A., and Crossfield, A.: Nearly $85 \%$ of tobacco smoke is invisible - a confirmation of previous claims, Tob. Control, 22, 429-429, https://doi.org/10.1136/tobaccocontrol-2012-050475, 2013.

Hasenfratz, D., Saukh, O., Sturzenegger, S., and Thiele, L.: Participatory Air Pollution Monitoring Using Smartphones, 2nd International Workshop on Mobile Sensing, 1-5, 2012.

Herberger, S., Herold, M., Ulmer, H., Burdack-Freitag, A., and Mayer, F.: Detection of human effluents by a MOS gas sensor in correlation to VOC quantification by GC/MS, Build Environ., 45, 2430-2439, https://doi.org/10.1016/j.buildenv.2010.05.005, 2010.

Hernandez, G., Arias, O., Buentello, D., and Jin, Y.: Smart Nest Thermostat?, A Smart Spy in Your Home, Black Hat USA, 1-8, 2014.

Jones, A. P.: Indoor air quality and health, Atmos. Environ., 33, 4535-4564, https://doi.org/10.1016/S1352-2310(99)00272$1,1999$.

Kadosaki, M., Sakai, Y., Tamura, I., Matsubara, I., and Itoh, T.: Development of an oxide semiconductor thick film gas sensor for the detection of total volatile organic compounds, Electr. Commun. Jpn., 93, 34-41, https://doi.org/10.1002/ecj.10190, 2010.
Kahkonen, E., Zitting, A., Airo, E., Valkonen, J., and Leikas, M.: Internet Questionnaire and Real-Time Indoor Air Quality Monitoring, Indoor Built Environ., 6, 331-336, 1997.

Kim, D. S., Jin Ching, B., and Son, S.-Y.: Implementation of a Low-Cost Energy and Environment Monitoring System Based on a Hybrid Wireless Sensor Network, J. Sensors, 2017, 461462, https://doi.org/10.1155/2017/5957082, 2017.

Koistinen, K., Kotzias, D., Kephalopoulos, S., Schlitt, C., Carrer, P., Jantunen, M., Kirchner, S., McLaughlin, J., Molhave, L., Fernandes, E. O., and Seifert, B.: The INDEX project: Executive summary of a European Union project on indoor air pollutants, Allergy: European Journal of Allergy and Clinical Immunology, 63, 810-819, https://doi.org/10.1111/j.1398-9995.2008.01740.x, 2008.

Kularatna, N. and Sudantha, B. H.: An Environmental Air Pollution Monitoring System Based on the IEEE 1451 Standard for Low-Cost Requirements, IEEE Sens. J., 8, 415-422, https://doi.org/10.1109/JSEN.2008.917477, 2008.

Landsberger, H. A. and Ithaca, N. Y.: Hawthorne revisited: Managment and the worker, its Critics and Developments in Human Relations in Industry, Cornell Studies in industrial and Labor Relations, 9, 132 pp., 1958.

Lee, D. D.: Environmental gas sensors, IEEE Sens. J. 1, 214-224, https://doi.org/10.1109/JSEN.2001.954834, 2001.

Liu, X., Cheng, S., Liu, H., Hu, S., Zhang, D., and Ning, H.: A Survey on Gas Sensing Technology, Sensors, 12, 9635-9665, https://doi.org/10.3390/s120709635, 2012.

Manikonda, A., Zikova, N., Hopke, P. K., and Ferro, A.: Laboratory assessment of low-cost PM monitors, J. Aerosol Sci., 102, 2940, https://doi.org/10.1016/j.jaerosci.2016.08.010, 2016.

Matsuoka, Y. and Fisher, E. J.: Context adaptive cool-to-dry feature for HVAC controller, Patent US9696735 B2, US, 2017.

Mukaka, M. M.: A guide to appropriate use of Correlation coefficient in medical research, Malawi Med. J., 24, 69-71, https://doi.org/10.1016/j.cmpb.2016.01.020, 2012.

Myles, P. S. and Cui, J.: Using the Bland-Altman method to measure agreement with repeated measures, Brit. J. Anaesth., 99, 309311, https://doi.org/10.1093/bja/aem214, 2007.

Porteous, C. D.: Sensing a Historic Low- $\mathrm{CO}_{2}$ Future, edited by: Mazzeo, D. N., Chemistry, Emission Control, Radioactive Pollution and Indoor Air Quality, InTech, 213-246, 2011.

Postolache, O. A., Pereira, J. M. D., and Girao, P. M. B. S.: Smart Sensors Network for Air Quality Monitoring Applications, IEEE T. Instrum. Meas., 58, 3253-3262, https://doi.org/10.1109/TIM.2009.2022372, 2009.

Semple, S., Apsley, A., and MacCalman, L.: An inexpensive particle monitor for smoker behaviour modification in homes, Tob. Control, 22, 295-298, https://doi.org/10.1136/tobaccocontrol2011-050401, 2013a.

Semple, S., Ibrahim, A. E., Apsley, A., Steiner, M., and Turner, S.: Using a new, low-cost air quality sensor to quantify secondhand smoke (SHS) levels in homes, Tob. Control, 24, 153-158, https://doi.org/10.1136/tobaccocontrol-2013-051188, 2013 b.

SENSIRION: Datasheet SHT20P Humidity and Temperature Sensor IC, available at: https://www.mouser.com/ds/2/682/ Sensirion_Humidity_Sensors_SHT20_Datasheet-1274196.pdf (last access: 4 May 2018), 2014. 
Sousan, S., Koehler, K., Hallett, L., and Peters, T.: Evaluation of consumer monitors to measure particulate matter, J. Aerosol Sci., 107, 123-133, https://doi.org/10.1016/j.jaerosci.2017.02.013, 2017.

Tong, Z., Xiong, X., and Patra, P.: Miniaturized $\mathrm{PM}_{2.5}$ Particulate Sensor Based on Optical Sensing, in: 2015 ASEE-NE Conference, Boston, US, 30 April-2 May 2015, 6604 pp., Boston: ASEE, 2015.

Ulmer, H. and Herberger, S.: New Developments in VOC Sensing for DCV, in: 33rd AIVC and 2nd TightVent Conference - Optimising Ventilative Cooling and Airtightness for [Nearly] ZeroEnergy Buildings, IAQ and Comfort, Copenhagen, Denmark: AIVC, 10-11 October 2012.

Wang, Y., Li J., Jing, H., Zhang, Q., Jiang, J., and Biswas, P.: Laboratory Evaluation and Calibration of Three Low-Cost Particle Sensors for Particulate Matter Measurement, Aerosol Sci. Tech., 49, 1063-1077, https://doi.org/10.1080/02786826.2015.1100710, 2015.

Watson, J.: The tin oxide gas sensor and its applications, Sens. Actuat., 5, 29-42, https://doi.org/10.1016/0250-6874(84)87004-3, 1984.

White, W. H.: Considerations in the use of ozone and $\mathrm{PM}_{2.5}$ data for exposure assessment, Air Qual. Atmos. Hlth., 2, 223-230, https://doi.org/10.1007/s11869-009-0056-9, 2009.
WHO: Air quality guidelines for Europe, WHO Regional Publications, European Series, No. 91., 2nd Edn., edited by: Theakston, F., Copenhagen: WHO Regional Publications, 2000.

WHO: WHO guidelines for indoor air quality: selected pollutants, 1st Edn., edited by: Theakston, F., Copenhagen: World Health Organization Regional Office for Europe, https://doi.org/10.1186/2041-1480-2-S2-I1, 2010.

$\mathrm{Yu}$, C. W. F. and Kim, J. T.: Low-carbon housings and indoor air quality, Indoor Built Environ., 21, 5-15, https://doi.org/10.1177/1420326X11431907, 2012.

Yu, T.-C., Lin, C.-C., Chen, C.-C., Lee, W.-L., Lee, R.-G., Tseng, C.-H., and Liu, S.-P.:, Wireless sensor networks for indoor air quality monitoring, Med. Eng. Phys., 35, 231-235, https://doi.org/10.1016/j.medengphy.2011.10.011, 2013.

Zikova, N., Hopke, P. K., and Ferro, A. R.: Evaluation of new low-cost particle monitors for $\mathrm{PM}_{2.5}$ concentrations measurements, J. Aerosol Sci., 105, 24-34, https://doi.org/10.1016/j.jaerosci.2016.11.010, 2017. 